\title{
DOES LEED CERTIFICATION SAVE ENERGY? EVIDENCE FROM FEDERAL BUILDINGS
}

\author{
Karen Clay \\ Edson R. Severnini \\ Xiaochen Sun \\ Working Paper 28612 \\ http://www.nber.org/papers/w28612 \\ NATIONAL BUREAU OF ECONOMIC RESEARCH \\ 1050 Massachusetts Avenue \\ Cambridge, MA 02138 \\ March 2021
}

We are grateful for invaluable comments and suggestions from Andrea La Nauze, Vivian Loftness, Kathleen Segerson, Yujie Xu, seminar participants at Carnegie Mellon University, and conference participants at the Association for Mentoring and Inclusion in Economics (AMIE)'s Workshop in Applied Microeconomics. We also gratefully acknowledge financial support from the Heinz College at Carnegie Mellon University. The views expressed herein are those of the authors and do not necessarily reflect the views of the National Bureau of Economic Research.

NBER working papers are circulated for discussion and comment purposes. They have not been peer-reviewed or been subject to the review by the NBER Board of Directors that accompanies official NBER publications.

(C) 2021 by Karen Clay, Edson R. Severnini, and Xiaochen Sun. All rights reserved. Short sections of text, not to exceed two paragraphs, may be quoted without explicit permission provided that full credit, including $(\odot$ notice, is given to the source. 
Does LEED Certification Save Energy? Evidence from Federal Buildings

Karen Clay, Edson R. Severnini, and Xiaochen Sun

NBER Working Paper No. 28612

March 2021

JEL No. O31,Q41,Q48,Q52

\section{ABSTRACT}

In the absence of first-best climate policy, energy efficiency has figured prominently among strategies to reduce carbon emissions. One of the most sought-after green certification in the building sector is the internationally recognized Leadership in Energy \& Environmental Design (LEED). This paper examines the effects of LEED certification on energy efficiency in federally owned buildings. Using propensity score matching and difference in differences models, we find no effect of LEED certification on average energy consumption. This reflects the fact that energy use is one of a number of attributes that receives scores under the LEED program. Buildings with above average energy scores have greater energy efficiency post-certification. Some other attributes, notably higher water scores, decrease energy efficiency post-certification. Trade-offs across LEED attributes account for the absence of energy savings on average. If energy efficiency is the primary policy goal, LEED certification may not be the most effective means to reach that goal.

Karen Clay

Heinz College

Carnegie Mellon University

5000 Forbes Avenue

Pittsburgh, PA 15213

and NBER

kclay@andrew.cmu.edu

Edson R. Severnini

Carnegie Mellon University

4800 Forbes Ave \#2114B

Pittsburgh, PA 15213

United States

ersevernini@gmail.com
Xiaochen Sun

H. John Heinz III College

Carnegie Mellon University

4800 Forbes Avenue

Pittsburgh, PA 15213.

xiaoches@andrew.cmu.edu 


\section{Introduction}

In the absence of first-best climate policy, energy efficiency has figured prominently among strategies to reduce carbon emissions. Nevertheless, ex-post outcomes of energy efficiency initiatives have fallen short of ex-ante model predictions. Possible explanations include behavioral failures such as inattention and myopia, the rebound effect, and product attribute trade-offs. ${ }^{1}$ One of the most sought-after green certification in the building sector is the internationally recognized Leadership in Energy \& Environmental Design (LEED). Despite causing increases in property values (Eichholtz, Kok and Quigley, 2010, 2013), it is not clear that certification would decrease energy consumption. Much like automakers trade off fuel economy for car weight or engine power to comply with attribute-based regulation (Knittel, 2011; Ito and Sallee, 2018), real estate developers may trade off energy savings for other attributes aimed at improving design and comfort in buildings. To the best of our knowledge, however, there is no credible evidence on the effectiveness of green certification programs in reducing energy consumption in commercial buildings, likely due to proprietary data restrictions. ${ }^{2}$

In this study, we examine the causal impact of LEED certification on energy consumption among federally owned buildings over the period 1990-2019, using a differencein-differences propensity score matching approach. The U.S. federal government has enormous direct and indirect influence on energy utilization in buildings. The building sector represented $39 \%$ of total U.S. energy consumption in 2019 , and over $12 \%$ of total greenhouse gas emissions (U.S. EIA, 2021). Commercial buildings alone accounted for $18 \%$ of energy consumption, and there appears to be opportunities for savings (U.S. DOE, 2020). Notably, commercial buildings owned by the federal government have historically consumed more energy than privately owned buildings (U.S. DOE, 2020), and their energy use information can be made accessible to the public.

Over the last twenty years, energy efficiency has been an increasing priority for the federal government. Legislation aimed at energy efficiency in federal buildings was introduced by the Energy Policy Act in 1992 and updated in 2005 (Sharp, 1992; Pombo and Thomas, 2005). Those policies set efficiency standards for federal buildings and reg-

\footnotetext{
${ }^{1}$ For reviews of this literature, see Gillingham, Newell and Palmer (2006, 2009), Allcott and Greenstone (2012), Gerarden, Newell and Stavins (2017), and Gillingham, Keyes and Palmer (2018).

${ }^{2}$ For analyses of energy efficiency in the residential sector, see for example Levinson (2016), Fowlie, Greenstone and Wolfram (2018), and Myers (2019).
} 
ulated new construction to comply with standards. In 2009, the American Recovery and Reinvestment Act and the Executive Order (EO) 13514 were released in the context of the Great Recession to further promote the green design of federal buildings. The EO required that all new construction and $15 \%$ of existing buildings meet the Guiding Principles for Federal Leadership in High Performance and Sustainable Buildings by 2015 (Obama, 2009). In response to this set of policies, the General Service Administration (GSA) announced a $\$ 5.55$ billion plan to improve their building performance. ${ }^{3}$

Retrofitting existing federally owned buildings and obtaining LEED certification for these retrofits was a major component of the GSA effort beginning in 2001 and accelerating after the 2008-2009 recession. Buildings are LEED certified based on the sum of scores across several attributes. As a result, buildings do not need to achieve high scores in energy efficiency if high scores are achieved in other areas, such as site sustainability, indoor environmental quality, or water efficiency. These trade-offs have some similarities to trade-offs in the U.S. Corporate Average Fuel Economy (CAFE) standards and Japanese fuel economy regulations (Knittel, 2011; Ito and Sallee, 2018).

This paper examines the extent to which LEED certified retrofits yielded energy savings. The analysis draws on data from the GSA's Energy Usage Analysis System (EUAS) for all federally owned buildings as well as data from the Green Building Information Gateway (GBIG). Inspired by Eichholtz, Kok and Quigley (2010, 2013), we use a difference-in-differences propensity score matching approach to estimate the causal effect of LEED certification on energy efficiency. Matching methods tackle selection on observables, and difference in differences controls for the presence of unobservables that under normal circumstances may lead to biased estimates. In our setting, propensity score matching addresses the fact that LEED certified buildings tend to be much larger than average. Then, the difference in differences estimation compares buildings that would be LEED certified before and after retrofitting with otherwise similar buildings that were not LEED certified.

We find that there were no energy savings from LEED certification, on average, and that this seems to be driven by trade-offs across LEED attributes. ${ }^{4}$ Our estimates show

\footnotetext{
${ }^{3}$ The Biden administration plan for energy and climate policy also considers "dramatic investments in energy efficiency in buildings, including completing 4 million retrofits" (see joebiden.com/clean-energy/).

${ }^{4}$ Because federal agencies had to "improve energy efficiency and reduce greenhouse gas emissions (...) through reduction of energy intensity by (...) 3 percent annually" (F.R., 2007, p.3919), this finding suggests that LEED certification did not generate any additional savings relative to that baseline.
} 
no effect of LEED certification on average energy consumption in $\mathrm{kBTUs} / \mathrm{ft}^{2}$. This reflects the fact that energy use is one of a number of attributes that receives scores under the LEED program. Buildings with higher energy scores have greater energy efficiency post-certification. This may reflect, for example, the adoption of high efficiency lighting and high efficiency HVAC. Having a one standard deviation higher energy score is associated with $17.2 \%$ lower energy usage in all buildings and $18.1 \%$ lower usage in office buildings. Some other attributes, notably higher water scores, decrease energy efficiency post-certification. This may reflect, for example, the use of sensors for water in sinks and toilets in bathrooms and sensors for water in landscaping. These trade-offs across LEED attributes seem to account for the absence of energy savings on average.

Our paper makes two contributions to the literature. First, we provide the first causal estimates of energy savings from the LEED program using data from federal government buildings. ${ }^{5}$ A number of engineering studies have compared the energy efficiency of LEED and non-LEED buildings (e.g., Wedding and Crawford-Brown, 2008; Scofield, 2009, 2013; Scofield and Doane, 2018). Like our paper, they have found no energy savings. ${ }^{6}$ None of these studies, however, provide causal estimates. USGBC states that there were $\$ 1.2$ billion in energy savings from the LEED certified buildings between 2015 and 2018 (U.S. Green Building Council, 2020b). These estimates, however, are based on comparisons with guidelines rather than examining the actual performance of buildings before and after retrofitting.

Second, we provide evidence suggesting that the absence of energy savings from the LEED certification is driven by the trade-offs across LEED attributes. The trade-offs are in some ways similar to the trade-offs in fuel economy regulations. Both Knittel (2011) and Ito and Sallee (2018) show that automobiles are designed to satisfy the increasingly stringent fuel standards through a secondary attribute - car weight - instead of improvement in car efficiency. Consistent with this pattern, our study finds that buildings with higher energy scores had lower energy consumption following retrofitting. ${ }^{7}$ Yet, buildings

\footnotetext{
${ }^{5}$ Our data does not include ex-ante model predictions of energy savings, so our analysis does not address the energy gap literature (e.g., Allcott and Greenstone, 2012; Levinson, 2016; Gerarden, Newell and Stavins, 2017; Fowlie, Greenstone and Wolfram, 2018; Gillingham, Keyes and Palmer, 2018).

${ }^{6}$ Notwithstanding, Eichholtz, Kok and Quigley (2010, 2013) find that LEED-certified commercial buildings command substantially higher rents and selling prices than otherwise identical buildings. Their evidence suggests that the "intangible" effects of the label itself may play a role in determining the values of green buildings in the marketplace. In fact, Matisoff, Noonan and Mazzolini (2014) find that marketing benefits due to LEED certification may be the primary drivers in the development of green buildings.

${ }^{7}$ Eichholtz, Kok and Quigley $(2010,2013)$ indeed find that variations in premiums paid for certified
} 
with high water scores had lower energy efficiency. ${ }^{8}$ These findings suggest that LEED is not the optimal program to pursue if energy reduction is the primary goal.

In what follows, Section 2 lays out the policy background and introduces the LEED program. Section 3 describes the data and summary statistics of the buildings in the analysis. Section 4 presents the empirical strategy. Section 5 reports the (lack of) energy savings from the LEED program, and discusses the heterogeneity of the treatment effects identifying a mechanism behind the estimated energy outcome. Section 6 concludes.

\section{Background}

The building sector represents $39 \%$ of the total energy consumption in the U.S. (U.S. EIA, 2021). A substantial portion of that consumption is thought to be wasted (U.S. DOE, 2020). Federal government buildings are regarded as less efficient and consume considerably more energy than non-government commercial buildings (U.S. EIA, 2016). As a result, there has been a growing attention to green building design and an increasing number of policies that regulate energy performance in federal buildings.

Energy efficiency efforts began in the 1990s and gained momentum in the 2000s. The standards for energy efficiency for federal buildings were first set by the Energy Policy Act in 1992 (Sharp, 1992). It comprehensively described the energy needs in the United States and aligned the building codes with energy efficiency codes. This policy was amended in 2005 to set energy reduction goals for the federal buildings between 2006 and 2015 (Pombo and Thomas, 2005). In response to the Great Recession of 2008-2009, the American Recovery and Reinvestment Act was released in 2009 to also promote green design in federal buildings (Obey, 2009). Later that year Executive Order (EO) 13514 was signed, requiring new construction and at least $15 \%$ of the existing buildings to comply with the Guiding Principles by 2015 (Obama, 2009). The Guiding Principles emphasized the improvement of building sustainability, within which energy performance was expected to be optimized (The Council on Environmental Quality, 2016). A Presidential Memorandum was issued in the next year to ensure the goals

buildings in the marketplace are systematically related to energy-saving characteristics. The attributes rated for thermal efficiency, as well as sustainability, contribute to premiums in rents and asset values.

${ }^{8}$ This finding is consistent with results from Kahn, Kok and Quigley (2014). Although their sample does not include government buildings, they find that commercial buildings that are newer and of higher quality consume more electricity, contrasting evidence for the residential sector (e.g., Levinson, 2016). 
could be properly achieved (Obama, 2011). The EO was revised in 2016 but there were no major changes in the requirements for building energy usage (Obama, 2015). Responding to these series of regulations, GSA announced a $\$ 5.55$ billion plan in 2010 to achieve significant savings from their buildings. Part of the focus was on LEED certification (Kampschroer, 2010).

LEED was developed by the U.S. Green Building Council (USGBC) to rate green building strategies across several categories. Unlike other widely recognized labels such as the Energy Star, which focuses on energy use, LEED certifies a building based on a comprehensive evaluation of six categories. The scoreboard includes energy and atmosphere, materials and resources, indoor environmental quality, sustainable sites, water efficiency, and innovation in operations. The energy component accounts for the largest share, more than 30\%. This paper does not focus on the heterogeneous effects across LEED tiers because we have a limited number of observations within each tier bin. ${ }^{9}$ Instead, we investigate the impacts associated with the component scores directly. Appendix I provides a more detailed introduction to the LEED program, and Appendix Table A.1 presents an overview of some important credit categories for each component in the LEED score board.

\section{Data Sources and Summary Statistics}

This study uses three sources of data: the Energy Usage Analysis System (EUAS) dataset from the General Services Administration (GSA), the Green Building Information Gateway (GBIG) reports, and weather data from National Oceanic and Atmospheric Administration (NOAA). The EUAS dataset provides monthly energy consumption data for GSA buildings in the 48 contiguous American states plus District of Columbia for the period 1990 to 2019 . We aggregate the data to the annual level. ${ }^{10}$

The GBIG reports provide information on LEED certified buildings. Based on the

\footnotetext{
${ }^{9}$ For the record, LEED-certified projects earn one of four rating levels: certified, silver, gold or platinum. Prior studies in real estate and marketing have examined tier bunching (Matisoff, Noonan and Mazzolini, 2014; Rysman, Simcoe and Wang, 2020), but we lack enough data variation in our setting.

${ }^{10}$ Data are missing for some building-month observations. For the months with missing data, we use the average consumption of the individual building in that year to interpolate those values. Later we report that our findings are similar if we use monthly data, although slightly less precisely estimated, and in unreported analysis we find no noticeable heterogeneity by season of the year.
} 
street address, we match these reports to the EUAS dataset. Specifically, it includes facility address, program registration and certification dates, certified square footage, and scores for each LEED category. The NOAA data allow us to control for variation in weather across time and building location.

Appendix Table A.2 provides information on the number of buildings in the dataset. We restrict attention to buildings owned by the federal government, because the LEED buildings are all federally owned. This reduces the sample size substantially. We only keep buildings with at least 8 years before and 4 years after the treatment date to ensure a balanced panel while still keeping enough observations for estimation. This drops 43 LEED buildings, many of which are new construction. A few LEED buildings are dropped due to incomplete data. Our analysis focuses on the 60 LEED buildings with complete LEED component score data. ${ }^{11}$ Appendix Table A.3 shows the type of LEED programs for these 60 LEED buildings. More than half of those buildings are existing buildings which obtained LEED certification via retrofitting.

Two issues are worth noting with respect to LEED buildings. First, buildings can be LEED certified for a subset of the overall square footage. The guidelines published by U.S. Green Building Council (2020a) use 5\% as the lower bound for certification. Appendix Figure A.1 shows the distribution of the certified ratio. Most LEED-certified buildings in our sample obtain certification for a high share of the overall square footage.

Second, GBIG reports provide both registration and certification dates for LEED buildings. Because there is no mandatory timeline for a building to achieve LEED certification after registering with the program, it is hard to determine when the building retrofit actually starts. Thus, we focus on the awarded date of the LEED certification. Awarding of the certification only occurs after the completion of retrofits. Some LEED programs also require one year of "performance period" before granting a building the initial certification so as to monitor its operation after the renovation (Wehe, 2020). ${ }^{12}$

Building energy consumption can be measured as site energy, which is reported by the EUAS dataset, or as source energy. Site energy is the amount of heat and electricity con-

\footnotetext{
${ }^{11}$ The estimates are qualitatively similar to our main results when conducting the analysis with an unbalanced panel and the incomplete score sample.

${ }^{12}$ The LEED EB program - LEED for Existing Buildings - is the program requiring a "performance period" to monitor operations before granting the certification. As mentioned above, over half of the buildings in our main sample are certified by this type of program.
} 
sumed by a building as reflected in the utility bill, whereas source energy represents the total amount of raw fuel that is required to operate a building, incorporating all transmission, delivery, and production losses (U.S. EPA, 2020). Since both site and source energy can be served as the benchmark for LEED compliance (U.S. Green Building Council, 2018), we calculate source energy using the U.S. EPA (2019) Technical Reference. The estimates from site and source energy are similar. We report results for site energy in the main text and report selected results for source energy in the appendix.

Table 1, Panel A, provides summary statistics for LEED and non-LEED buildings,

including pre-treatment energy use intensity and building size. Energy use intensity (EUI) is defined as the ratio of total energy consumption and the square footage of a building. Pre-treatment is defined as the first 12 months that a building appears in the dataset. It also reports the differences between treated and untreated building groups. LEED buildings are significantly larger than non-LEED buildings in square footage. The federal government appears to have focused on the largest buildings for LEED certification. The majority of LEED and non-LEED buildings are office buildings, and most of the remaining buildings are courthouses.

Table 1, Panel B, provides the number of LEED and non-LEED buildings, and Panel $\mathrm{C}$ reports average LEED program attributes in our sample. Because the LEED program has changed slightly over time, we report the component score divided by the total achievable score. Given that the component scores for materials and resources, indoor environmental quality, and innovation in operations are highly positively correlated (see Appendix Table A.4), we combined these into a single measure. Histograms of the scores are shown in Appendix Figure A.2. To facilitate comparison, in the analysis the component scores and the certification ratio are all standardized to have mean zero and standard deviation one.

\section{Empirical Strategy}

This section introduces the methodology to estimate the energy savings from the LEED certification. Building on Eichholtz, Kok and Quigley (2010, 2013), we implement a two-stage strategy to address differences in pre-treatment characteristics of the LEED and non-LEED buildings, and then compare the two groups to infer the energy reduc- 
tions brought about by the LEED program. Specifically, propensity score matching is employed in the first stage to construct a sub-sample of the untreated buildings with similar characteristics to treated buildings. After that, difference in differences models are applied in the second stage with the newly constructed sample to evaluate the energy outcome from the certification.

Our paper implements several matching algorithms and estimates both site and source energy savings from the LEED program. These specifications generate similar estimates. Thus, we report the results for site energy with a five nearest-neighbor $(5 \mathrm{NN})$ propensity score matching in the main discussion, leaving other cases for the appendix. ${ }^{13}$

\subsection{First Stage: Propensity Score Matching}

In the first stage of the analysis, we regress the LEED indicator on building characteristics and obtain the propensity scores. Following Caliendo and Kopeinig (2008), we use a probit regression to bound the LEED indicator in the range of $[0,1]$.

The basic specification is

$$
\operatorname{Pr}\left(D_{i}=1 \mid X_{i}\right)=\Phi\left(X_{i}^{\prime} \gamma\right)
$$

where $D$ is a dummy variable equal to one if a building $i$ is LEED certified and zero otherwise. $X$ represents a vector of building characteristics that may differ between the treated and untreated buildings, including building size and the pre-treatment energy use intensity (EUI). Although the two groups of buildings seem comparable in the pretreatment consumption from Table 1 , this variation is still included in the propensity score estimation to ensure a similar consumption pattern between the treated and untreated groups after matching. Moreover, we also incorporate the polynomial forms of these variables in the $X$ to address biases that might arise from a specific functional form. ${ }^{14}$

Figure 1a shows the distribution of the propensity scores before matching. The horizontal axis represents the propensity score while the vertical axis corresponds to the

\footnotetext{
${ }^{13}$ The regression results for other cases are reported in Appendix Table A.5.

${ }^{14}$ The estimated propensity scores become stable after having the energy consumption terms with third or higher power and the building size term with fourth or higher power. For this reason, the $X$ includes: pre-treatment site $\log (E U I)^{n}(n=1,2,3)$; pre-treatment source $\log (E U I)^{n}(n=1,2,3)$; building $\operatorname{size}^{n}(n=1,2,3)$. We also conduct a robustness check to only match on site energy or source energy. The estimates are similar to our main results.
} 
proportions of buildings that fall into each propensity score bin. It indicates good common support if the distribution of the propensity scores is similar for the two groups. We see from the figure that the treated buildings are concentrated between the propensity score of 0.1 and 0.3 , while the untreated buildings are right-skewed with many of them falling in the first propensity score bin. With the estimated propensity score, we match the non-LEED buildings to the LEED buildings using $k$-nearest neighbors $(k N N)$ with replacement. This method matches $k$ untreated buildings to each treated building that share similar propensity scores, so as to create a subset of buildings that are comparable in size and baseline energy consumption. ${ }^{15}$ Because this approach allows the non-LEED buildings to be matched more than once, there could be duplicate buildings in the untreated group. Figure 1b shows the propensity score distribution for treated and untreated buildings after matching with five nearest neighbors $(5 \mathrm{NN})$. We see that the untreated buildings are now more evenly spread across the propensity score bins. More importantly, the distributions of the scores are similar across the two groups, which supports the validity of the matching results. In this matching process, every building in the treatment group is able to find a relatively good match. Appendix Figure A.3 shows the locations of LEED and non-LEED buildings before and after matching.

Table 1, Panel A, also reports the descriptive statistics of LEED and non-LEED buildings after matching with 5NN. The gap in building size between the two groups is greatly reduced after matching and becomes no longer statistically significant. Meanwhile, the difference in the pre-treatment energy use intensity also remains insignificant. These statistics provide supporting evidence for the common support assumption, which is useful in the second-stage analysis.

\subsection{Second Stage: Difference-in-Differences Models}

In the second stage of the analysis, we estimate the energy savings from the LEED program. The specification is as follows:

$$
\ln \left(E U I_{i t}\right)=\theta T_{i t}+X_{i t}^{\prime} \beta+\gamma_{i}+\lambda_{t}+\epsilon_{i t}
$$

\footnotetext{
${ }^{15}$ If the propensity score of a treated building is higher than the maximum or lower than the minimum score of any untreated buildings, this treated unit would be considered an outlier and dropped from the dataset. None of the LEED buildings are dropped.
} 
where subscript $i$ refers to each individual building $i$, and $t$ refers to year $t .{ }^{16}$ The dependent variable $\ln \left(E U I_{i t}\right)$ is the energy use intensity in logarithm form. $T_{i t}$ is the treatment indicator equal to 1 if building $i$ in year $t$ is LEED certified. ${ }^{17} X_{i t}$ is a vector that captures weather variation, which includes annual cooling degree days (CDDs) and annual heating degree days (HDDs). $\gamma_{i}$ represents a set of building fixed effects, and $\lambda_{t}$ a set of year fixed effects. Because the matching with replacement in the first stage can introduce duplicate buildings in the untreated group, the regression is weighted by the number of repeated observations in the dataset. ${ }^{18}$

To examine the parallel trends assumption, we carry out an event study analysis to show the energy consumption difference between the treated and untreated groups each year relative to the difference in the reference year. Because the LEED buildings are certified in different years, we treat the certification year as year zero. After that, lead and lag terms are created for years before and after the certified year. Our specification leaves out the -1 year from the regression, as that year corresponds to the beginning of the "performance period" discussed earlier. That is, we assume building renovations for the LEED buildings are completed at least one year before the certified date. Hence, the -1 year is the reference year in our setting. Specifically, the regression is run as follows

$$
\ln \left(E U I_{i t}\right)=\gamma_{i}+\lambda_{t}+\sum_{\tau=2}^{q} \delta_{+\tau} D_{i, t+\tau}+\sum_{\tau=0}^{m} \delta_{-\tau} D_{i, t-\tau}+\tilde{D}_{i t}^{\prime} \delta+X_{i t}^{\prime} \alpha+\epsilon_{i t}
$$

The first sum allows for $q$ leads $\left(\delta_{+1}, \ldots, \delta_{+q}\right)$ and $D_{i, t+\tau}$ equals to 1 if the calendar year $t$ is $\tau$ year(s) before the building is LEED certified. Similarly, the second sum allows for $m$ lags $\left(\delta_{0}, \ldots, \delta_{-m}\right)$ and $D_{i, t-\tau}$ equals to 1 if the calendar year $t$ is $\tau$ year(s) after LEED certification. Because our data is balanced with 8 years pre-treatment and 4 years post-treatment, $q$ and $m$ are set to be 8 and 4 , respectively. $\tilde{D}_{i t}^{\prime}$ is a vector that captures the sum of lead and lag terms that are far away from the treatment year to minimize noise in the estimation. It represents the endpoint restrictions (Kline, 2012).

\footnotetext{
${ }^{16}$ Appendix Table A.6 estimates this specification with monthly data. The results are almost identical to our main findings, although slightly less precisely estimated. In unreported analysis available upon request we find no noticeable heterogeneity by season of the year.

${ }^{17}$ As a preview of the results of the main analysis, Appendix Figure A.4 shows the full distribution of energy consumption for LEED and non-LEED buildings, before and after certification. Appendix Figure A.5 displays the differences in energy consumption between LEED and non-LEED buildings over time.

${ }^{18}$ More than half of the non-LEED buildings are matched only once, but there are cases when nonLEED buildings are matched more than once. The maximum number of matches is 5 . We also present results weighted by both building size and duplicates. Estimates are shown in Appendix Table A.7, and indicate similar patterns as the main results.
} 


\section{Results}

\subsection{Impacts of LEED Certification on Energy Consumption}

Table 2 shows that LEED certification did not have a statistically significant effect on energy consumption. The coefficients on LEED certification in columns (1)-(8) are consistently small and not statistically significant. Recall that the certification ratio and the component scores are all standardized to have a mean of zero and a standard deviation of one. Thus, in columns (2)-(8) the coefficients of the interactions represent the effects of a one standard deviation increase in the corresponding variables. Column (7) shows the results for all buildings, and column (8) restricts attention to office buildings.

Buildings with higher energy scores had lower energy consumption following certification. In columns (7) and (8), a one standard deviation increase in energy score was associated with a nearly $17.2 \%$ decrease in energy consumption in all buildings and $18.1 \%$ lower in office buildings. LEED certification was associated with improvements in energy efficiency for buildings where energy efficiency was a focus.

This reduction in energy consumption is economically meaningful. The average energy intensity of the LEED buildings in the year they were certified is approximately $21 \mathrm{kWh} / \mathrm{ft}^{2}$. Assuming the electricity price is between 5-18 cents/kWh, the annual savings associated with the reduction are 18-65 cents $/ \mathrm{ft}^{2} .{ }^{19}$ The typical cost of green retrofit for an entire building is anywhere between $\$ 2-7 / \mathrm{ft}^{2}$ (Lockwood, 2009), and thus the average payback year of the LEED retrofit is around 7-25 years. ${ }^{20}$ This implied payback period is reasonable, given that the usual payback time for an energy efficiency program is around 2-15 years depending on the building's age and other information. Moreover, the payback period is relatively consistent with the requirements from the Obama (2011)'s Memorandum if the retrofit is done properly. The Memorandum specified "agencies shall fully implement energy conservation measures (ECMs) in federal buildings with a payback time of less than 10 years." These calculations suggest that if the LEED certification has relied heavily on the energy attribute, which is the energy performance optimization,

\footnotetext{
${ }^{19}$ The electricity price varies across states. Based on the U.S. EIA (2020)'s monthly report, California has the highest electricity price, 18.39 cents/kWh, while Nevada has the lowest electricity price, 4.59 cents/kWh.

${ }^{20}$ Assuming the average retrofit cost is $\$ 4.5 / \mathrm{ft}^{2}$, the payback year is calculated as PaybackPeriod $=$ $\frac{\text { RetrofitCost }}{\text { Savings }}$.
} 
the energy savings should be non-trivial. As shown in Appendix Table A.1, a building can reach high energy scores by installing efficient lighting and HVAC, for example.

On the other hand, buildings with higher water scores had higher energy consumption following certification. In columns (7) and (8), a one standard deviation increase in water score was associated with a $7-11 \%$ increase in energy consumption. This suggests that some buildings are focusing on attributes other than energy to achieve LEED certification. As highlighted in Appendix Table A.1, this may reflect, for example, the use of sensors for water in sinks and toilets in bathrooms and sensors for water in landscaping.

To illustrate the trade-offs between energy and water, Appendix Table A.8 presents the effects for different combinations of the energy and water scores. For example, at the extremes, a building that had a one standard deviation higher energy score and one standard deviation lower water score than average would have energy use that was $24.7 \%$ lower than a non-LEED building. Conversely, a building that had a one standard deviation lower energy score and one standard deviation higher water score than average would have energy use that was $23.9 \%$ higher than a non-LEED building. A building that had one standard deviation higher energy and water scores would have energy use that was $10.5 \%$ lower than a non-LEED building. Similar conclusions hold when restricted to office buildings.

Figure 2a presents the results of the event study. The post-treatment coefficients are all around zero, which echo the results from the difference-in-differences model. The $x$ axis represents a timeline of the LEED certification procedure. Buildings are certified at year 0 , and the reference year is set at year -1 . The average registration year of the LEED buildings is 3 years before the certified date. The $y$-axis is the energy savings from the LEED program in each year relative to the reference year. As observed, all coefficients are around zero except for some fluctuations around the registration year such as year -4 . We suspect these negative values are a result of building renovation preparation when occupants of the buildings are requested to leave the buildings for the retrofit to begin. With fewer residents remaining in the buildings, consumption would decrease. Other than that, the pre-trend looks flat and seems to supports the parallel trends assumption needed for our difference-in-differences approach. 


\subsection{Robustness Checks}

One possible reason for the lack of improvement in LEED certified buildings postcertification might be that the matched untreated buildings are also improving their energy efficiency over time. The EUAS database has information on upgrades that occurred in both LEED buildings and non-LEED buildings. In fact, approximately half of the buildings in the dataset have adopted energy conservation strategies, regardless of their LEED status. These upgrades include advanced metering, building envelope, building tune up or utility improvement, HVAC, indoor environmental quality, lighting, renewable energy, water efficiency, and others. Buildings might adopt more than one of these upgrades, and they are not necessarily completed in the same year. Appendix Figure A.6 shows the completion year of the first conservation initiative the buildings participated in. As indicated in the figure, most of the conservation measures were finished in 2011 for both LEED and non-LEED buildings. There is no indication that buildings with LEED certification must have to adopt those upgrades. In fact, the correlation between LEED certification and participation in any energy efficiency initiative is very low, -0.036. Further, most of the LEED buildings completed energy conservation upgrades before their certification, as revealed by Appendix Figure A.7.

Table 3 shows that our results are robust to the inclusion of upgrades as controls and dropping buildings with low certification ratios. Columns (1) and (2) re-estimate the earlier specifications but with these improvements as controls. All control variables in the table are indicator variables. They equal 1 when building $i$ in year $t$ has completed the upgrade, and zero otherwise. As shown in the columns, the results are similar to Table 2. To explore the effect of low certification ratios, we drop the 7 LEED buildings with certification ratios below 50\%. Results are shown in columns (3) and (4). Comparing to our main results in Table 2, the estimates are similar as well.

To investigate the regional impacts on the energy component score and water component score in LEED buildings, Appendix Figure A.8 plots the score distributions across four census regions. Notice that the energy scores in the Midwest are comparable to those in the South, despite the contrasting climate zones of these two regions. Likewise, the water component score distributions are identical across all four regions. Places with water scarcity problem, such as the West, do not perform better in water conservation. 
Appendix Table A.5 shows that our results are robust to the number of nearest neighbors used in the matching procedure, and to using source rather than site energy. Appendix Figure A.9 suggests that the parallel trends assumption seems to hold in all four cases. The effects of different attributes, notably energy and water scores, are similar to the main estimates reported in Table 2.

As a falsification test, we run the event study regressions only with the non-LEED buildings. Although we implemented the propensity score matching, it would still be a concern if the untreated buildings are affected by some shocks that are missed from the difference-in-differences model but would drive down their energy use intensity. We repeat the first and second stage regressions with only the non-LEED buildings and report the $\delta$ 's from Equation (3). Detailed procedures for this falsification test can be

found in Appendix II. If shocks do not play a major role in our findings, all the $\delta$ 's should be around zero. Figure $2 \mathrm{~b}$ plots the results for $5 \mathrm{NN}$ matching. The coefficients are all close to zero. This pattern also holds when conducting the analysis with source energy and the 3NN matching, as displayed in Appendix Figure A.10.

\section{Concluding Remarks}

The U.S. federal government has implemented a series of policies to improve energy efficiency and sustainability of the federal buildings. Leadership in Energy \& Environmental Design (LEED) certification was one important focus of this effort. This paper investigates the energy savings yielded by the certification. By employing propensity score matching and difference in differences models, we estimate the causal effects of LEED certification on energy consumption of federally owned buildings.

We have two primary findings. First, our estimates show no effect of LEED certification on average energy consumption measured in $\mathrm{kBTUs} / \mathrm{ft}^{2}$. Second, the absence of an effect seems to be driven by trade-offs across LEED attributes. Buildings with higher energy scores have greater energy efficiency post-certification. Some other attributes, notably higher water scores, decrease energy efficiency post-certification. These trade-offs across LEED attributes seems to account for the absence of energy savings on average.

Our findings have substantial policy implications. Although the USGBC has been 
revising the LEED scoreboard to increase emphasis on the energy component, ${ }^{21}$ the trade-offs inherent in LEED certification are likely to remain. If energy efficiency is the primary policy goal, LEED certification may not be the most effective means to reach that goal. The Biden administration plan considers "dramatic investments in energy efficiency in buildings, including completing 4 million retrofits" (see joebiden.com/clean-energy/). Attention should be paid on designing policies that provide the intended incentives.

\footnotetext{
${ }^{21}$ In 2016, for example, USGBC members voted to increase the minimum simulated improvement in energy performance for new buildings from 10 to $18 \%$, and for major renovations to existing buildings from 5 to $14 \%$ (see usgbc.org/credits/core-shell-new-construction/v2009/eap2). Interestingly, they state that "[t]he proposed changes are based on user and volunteer feedback" (see usgbc.org/articles/leed2009-energy-performance-update). It may well be the case that users were already noticing in practice what we have found in this study.
} 


\section{References}

Allcott, Hunt, and Michael Greenstone. 2012. "Is There an Energy Efficiency Gap?" Journal of Economic Perspectives, 26(1): 3-28.

Caliendo, Marco, and Sabine Kopeinig. 2008. "Some Practical Guidance for the Implementation of Propensity Score Matching." Journal of Economic Surveys, 22(1): 3172 .

Eichholtz, Piet, Nils Kok, and John M. Quigley. 2010. "Doing Well by Doing Good? Green Office Buildings." American Economic Review, 100(5): 2492-2509.

Eichholtz, Piet, Nils Kok, and John M. Quigley. 2013. "The Economics of Green Buildings." Review of Economics and Statistics, 95(1): 50-63.

Fowlie, Meredith, Michael Greenstone, and Catherine Wolfram. 2018. "Do Energy Efficiency Investments Deliver? Evidence from the Weatherization Assistance Program." Quarterly Journal of Economics, 133(3): 1597-1644.

F.R., Federal Register. 2007. "Executive Order 13423-Strengthening Federal Environmental, Energy, and Transportation Management." Federal Register - Presidential Documents, 72(17): 3917-3923.

Gerarden, Todd D., Richard G. Newell, and Robert N. Stavins. 2017. "Assessing the Energy-Efficiency Gap." Journal of Economic Literature, 55(4): 1486-1525.

Gillingham, Kenneth, Amelia Keyes, and Karen Palmer. 2018. "Advances in Evaluating Energy Efficiency Policies and Programs." Annual Review of Resource Economics, 10(1): 511-532.

Gillingham, Kenneth, Richard G. Newell, and Karen Palmer. 2009. "Energy Efficiency Economics and Policy." Annual Review of Resource Economics, 1(1): 597620.

Gillingham, Kenneth, Richard Newell, and Karen Palmer. 2006. "Energy Efficiency Policies: A Retrospective Examination." Annual Review of Environment and Resources, 31(1): 161-192.

Ito, Koichiro, and James M Sallee. 2018. "The Economics of Attribute-Based Regulation: Theory and Evidence from Fuel Economy Standards." Review of Economics and Statistics, 100(2): 319-336.

Kahn, Matthew E., Nils Kok, and John M. Quigley. 2014. "Carbon Emissions from the Commercial Building Sector: The Role of Climate, Quality, and Incentives." Journal of Public Economics, 113: 1-12.

Kampschroer, Kevin. 2010. "Statement of Kevin Kampschroer." Available at https://www.gsa.gov/about-us/newsroom/congressional-testimony/ federal-green-buildings, accessed on 2020-03-30. 
Kline, Patrick. 2012. "The Impact of Juvenile Curfew Laws on Arrests of Youth and Adults." American Law and Economics Review, 14(1): 44-67.

Knittel, Christopher R. 2011. "Automobiles on Steroids: Product Attribute Trade-offs and Technological Progress in the Automobile Sector." American Economic Review, 101(7): 3368-99.

Levinson, Arik. 2016. "How Much Energy Do Building Energy Codes Save? Evidence from California Houses." American Economic Review, 106(10): 2867-94.

Lockwood, Charles. 2009. "Building Retro." Urban Land Magazine.

Matisoff, Daniel C, Douglas S Noonan, and Anna M Mazzolini. 2014. "Performance or Marketing Benefits? The Case of LEED Certification." Environmental Science 85 Technology, 48(3): 2001-2007.

Myers, Erica. 2019. "Are Home Buyers Inattentive? Evidence from Capitalization of Energy Costs." American Economic Journal: Economic Policy, 11(2): 165-88.

Obama, Barack. 2009. "Federal leadership in environmental, energy, and economic performance." Executive Order (13514) of October, 5. Available at https: //www .govinfo.gov/content/pkg/DCPD-200900783/pdf/DCPD-200900783.pdf, accessed on 2018-12-19.

Obama, Barack. 2011. "Implementation of Energy Savings Projects and PerformanceBased Contracting for Energy Savings." Presidential Memorandum. Available at https://obamawhitehouse.archives.gov/the-press-office/2011/12/02/ presidential-memorandum-implementation-energy-savings-projects-and-perfo, accessed on 2018-12-19.

Obama, Barack. 2015. "Planning for federal sustainability in the next decade." Executive Order (13693) of March. Available at https://www.govinfo.gov/content/pkg/ FR-2015-03-25/pdf/2015-07016.pdf, accessed on 2019-05-01.

Obey, David R. 2009. "American Recovery and Reinvestment Act of 2009." Available at https://www . congress.gov/bill/111th-congress/house-bill/1, accessed on 2019-04-30.

Pombo, Richard W., and William M. Thomas. 2005. "Energy Policy Act of 2005." Available at https://www.govinfo.gov/content/pkg/PLAW-109pub158/ html/PLAW-109publ58.htm, accessed on 2019-02-21.

Rosa, Megan. 2016. "Looking Back: LEED History." Available at https://sigearth. com/leed-history/, accessed on 2021-01-10.

Rysman, Marc, Timothy Simcoe, and Yanfei Wang. 2020. "Differentiation Strategies in the Adoption of Environmental Standards: LEED from 2000 to 2014." Management Science.

Scofield, John H. 2009. "Do LEED-certified buildings save energy? Not really...." Energy and Buildings, 41(12): 1386-1390. 
Scofield, John H. 2013. "Efficacy of LEED-certification in reducing energy consumption and greenhouse gas emission for large New York City office buildings." Energy and Buildings, 67: 517-524.

Scofield, John H, and Jillian Doane. 2018. "Energy performance of LEED-certified buildings from 2015 Chicago benchmarking data." Energy and Buildings, 174: 402-413.

Sharp, Philip. 1992. "Energy Policy Act of 1992." Available at https://afdc.energy . gov/files/pdfs/2527.pdf, accessed on 2019-02-21.

The Council on Environmental Quality. 2016. "Guiding principles for sustainable federal buildings and associated instructions." Available at https://www.sustainability.gov/pdfs/guiding_principles_for_sustainable_ federal_buildings-2016.pdf, accessed on 2020-01-15.

U.S. DOE. 2020. "About the commercial buildings integration program." Available at https://www.energy.gov/eere/buildings/ about-commercial-buildings-integration-program, accessed on 2019-04-30.

U.S. EIA. 2016. "Recent energy intensity decline in government buildings exceeds commercial sector average." Available at https://www .eia.gov/todayinenergy/detail . php?id=27972, accessed on 2019-04-30.

U.S. EIA. 2020. "Electric Power Monthly with Data for October 2020." Available at https://www.eia.gov/electricity/monthly/, accessed on 2021-01-10.

U.S. EIA. 2021. "How much energy is consumed in U.S. buildings?" Available at https://www.eia.gov/tools/faqs/faq.php?id=86\&t=1, accessed on 2021-02-24.

U.S. EPA. 2019. "Tecnical Reference." Available at https://portfoliomanager. energystar.gov/pdf/reference/Source\%20Energy.pdf, accessed on 2020-02-02.

U.S. EPA. 2020. "The difference between source and site energy." Available at https://www .energystar.gov/buildings/facility-owners-and-managers/ existing-buildings/use-portfolio-manager/understand-metrics/difference, accessed on 2020-01-27.

U.S. Green Building Council. 2018. "LEED v4 for Building Operations and Maintenance." Available at https://www.usgbc.org/resources/ leed-v4-building-operations-and-maintenance-current-version, accessed on 2020-02-01.

U.S. Green Building Council. 2020a. "LEED rating system." Available at https: //www . usgbc.org/leed, accessed on 2020-02-19.

U.S. Green Building Council. 2020b. "Why LEED." Available at https://www . usgbc.org/leed/why-leed, accessed on 2021-01-10.

Wedding, G Christopher, and Douglas Crawford-Brown. 2008. "Improving the link between the LEED green building label and a building's energy-related environmental metrics." Journal of Green Building, 3(2): 85-105. 
Wehe, Stacey. 2020. "Comparison of LEED Rating Systems." Available at https: //www.redvector.com/lms/userfiles/files/LEED_rating_systems.pdf, accessed on 2020-02-18. 


\section{Figures and Tables}

Figure 1: Propensity Score Distributions Between Treated and Untreated Buildings

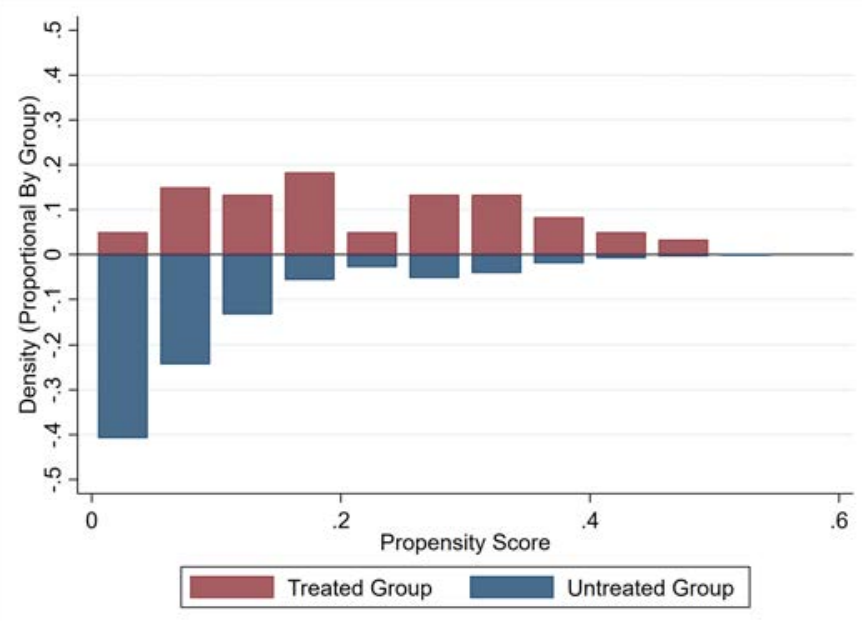

(a) Before Propensity Score Matching

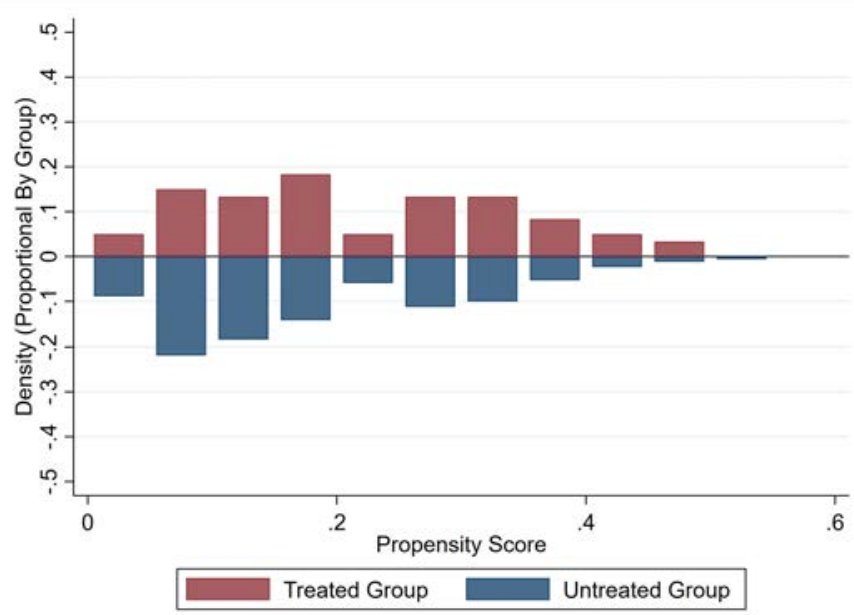

(b) After Propensity Score Matching

Notes: This figure presents the distributions of the propensity score for the LEED (red bars) and non-LEED (blue bars) federal buildings before and after matching. The horizontal axis displays the propensity score, and the vertical axis the proportion of buildings that falls into each propensity score bin. (a) shows the score distribution before matching; (b) presents the distribution after five-nearest-neighbor $(5 \mathrm{NN})$ propensity score matching with replacement. As observed, the propensity score distributions are similar between the two groups after matching in (b). The symmetric pattern between groups suggests that the common support assumption might hold in our analysis. Furthermore, our matching results also indicate that each individual LEED building is able to find a match from the untreated group. 
Figure 2: Energy Savings in Each Period Relative to the Savings in the Reference Year

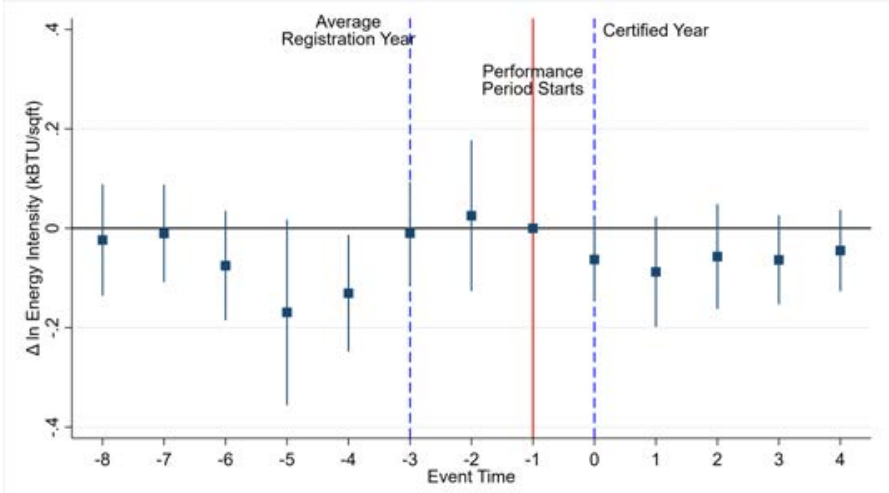

(a) Event Study Estimates

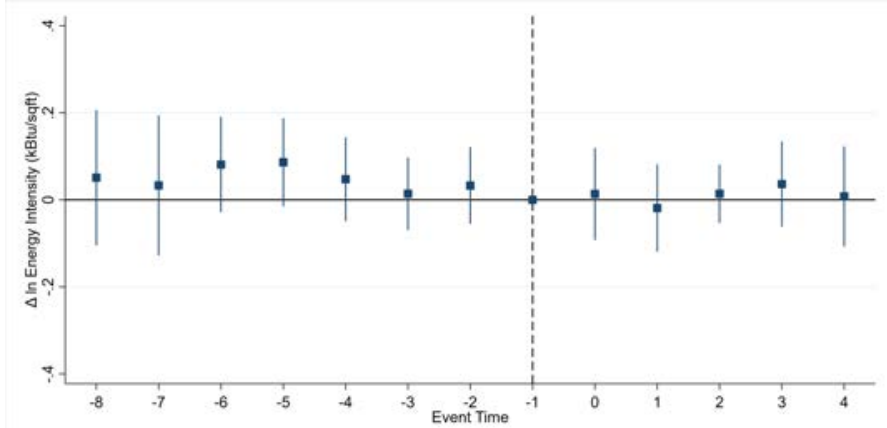

(b) Falsification Test on Non-LEED Buildings

Notes: This figure displays estimates from event study analyses for LEED certification among federal buildings. The vertical axis of the graphs displays the log difference between energy use intensity (in $\mathrm{kBTU} / \mathrm{ft}^{2}$ ) of treated and untreated federal buildings. (a) shows the event study results by plotting the coefficients $\delta$ 's from Equation (3). The reference year is set to be one year prior to the certification date, which is the first year of the "performance period". This period is required by some LEED programs to monitor building operations before granting certification in year zero. Typically, the performance period starts one year before the certified date. The average registration date for the LEED programs is approximately three years before the certified date. (b) provides the falsification test results with the non-LEED federal buildings only. For this test, we assign a treatment indicator to the untreated buildings based on their sizes, when compared to their LEED-certified counterparts. Detailed procedures of the test are discussed in Appendix II. The vertical bar around each estimated coefficient indicates the $95 \%$ confidence interval. 
Table 1: Descriptive Statistics for Buildings With and Without LEED Certification

\begin{tabular}{|c|c|c|c|c|c|}
\hline \multirow[t]{2}{*}{ Panel A: Building Characteristics } & \multirow{2}{*}{\multicolumn{2}{|c|}{$\begin{array}{l}\text { Pre-treatment Site } \\
\log (\mathrm{EUI})\left(\mathrm{kBTU} / \mathrm{ft}^{2}\right)\end{array}$}} & \multirow{2}{*}{\multicolumn{2}{|c|}{$\begin{array}{l}\text { Pre-treatment Source } \\
\log (\mathrm{EUI})\left(\mathrm{kBTU} / \mathrm{ft}^{2}\right)\end{array}$}} & \multirow{3}{*}{$\begin{array}{l}\text { Building Size } \\
\left(\mathrm{ft}^{2}\right) \\
407,537 \\
{[305,359]}\end{array}$} \\
\hline & & & & & \\
\hline Treated Buildings (Average) & $\begin{array}{l}4.072 \\
{[0.548]}\end{array}$ & & $\begin{array}{l}4.846 \\
{[0.516]}\end{array}$ & & \\
\hline Untreated Before Matching & $\begin{array}{l}4.083 \\
{[0.751]}\end{array}$ & & $\begin{array}{l}4.827 \\
{[0.705]}\end{array}$ & & $\begin{array}{l}218,808 \\
{[349,181]}\end{array}$ \\
\hline Difference Before Matching & $\begin{array}{l}-0.012 \\
(0.079)\end{array}$ & & $\begin{array}{l}0.019 \\
(0.074)\end{array}$ & & $\begin{array}{l}188,730^{* * *} \\
(42,678)\end{array}$ \\
\hline Untreated After 5NN Matching & $\begin{array}{l}4.078 \\
{[0.573]}\end{array}$ & & $\begin{array}{l}4.870 \\
{[0.533]}\end{array}$ & & $\begin{array}{l}413,145 \\
{[293,292]}\end{array}$ \\
\hline Difference After 5NN Matching & $\begin{array}{l}-0.006 \\
(0.078)\end{array}$ & & $\begin{array}{l}-0.024 \\
(0.073)\end{array}$ & & $\begin{array}{l}-5,607 \\
(42,905)\end{array}$ \\
\hline Panel B: Number of Buildings & Office & \multicolumn{2}{|c|}{ Courthouse } & Other & Total \\
\hline Treated Buildings & 43 & 14 & & 3 & 60 \\
\hline Untreated Before Matching & 298 & 123 & & 35 & 456 \\
\hline Untreated After 5NN Matching & 212 & 74 & & 14 & 300 \\
\hline Panel C: LEED Attributes & $\mathrm{CR}$ & ES & SS & WS & MIIS \\
\hline Treated Buildings (Average) & $\begin{array}{l}0.831 \\
{[0.238]}\end{array}$ & $\begin{array}{l}0.153 \\
{[0.068]}\end{array}$ & $\begin{array}{l}0.110 \\
{[0.057]}\end{array}$ & $\begin{array}{l}0.050 \\
{[0.027]}\end{array}$ & $\begin{array}{l}0.193 \\
{[0.086]}\end{array}$ \\
\hline
\end{tabular}

Notes: This table reports average characteristics of federal buildings with LEED certification and those without it, before and after five-nearest-neighbor (5NN) matching. The sample includes buildings observed over the period 1990-2019. Panel A reports building characteristic variables for buildings in the treated group and buildings in the untreated group before and after 5NN matching. Pre-treatment is defined as the first 12 months that a building appears in the dataset. EUI stands for energy use intensity, which is defined as the ratio of total energy consumption and the square footage of a building. Site energy is the amount of heat and electricity consumed by a building as reflected in the utility bill, whereas source energy represents the total amount of raw fuel that is required to operate a building, incorporating all transmission, delivery, and production losses. Panel B shows the number of buildings for treated and untreated buildings before and after matching. It is important to note that the untreated buildings are matched to LEED buildings with replacement, thus non-LEED buildings can appear more than once in the untreated group after $5 \mathrm{NN}$ matching. Panel $\mathrm{C}$ presents averages of different attributes in the LEED program for LEED-certified buildings. CR stands for certified ratio, and refers to the fraction of a building square footage that is LEED-certified. ES, SS, WS, and MIIS represent the component score proportions evaluated by the LEED program: energy and atmosphere, sustainable sites, water efficiency, and the combination of material, indoor environment, and innovation, respectively. Score proportion is defined as the ratio of the component score and the total achievable score in the LEED program. Standard deviations are reported in brackets, and standard errors clustered by building in parentheses. ${ }^{* * *}$ denotes statistical significance at the $1 \%$ level, ${ }^{* *}$ at the $5 \%$ level, and ${ }^{*}$ at the $10 \%$ level. 
Table 2: Energy Use Intensity Impacts from the LEED Program and Heterogeneity Analysis Results Regarding Different Program Attributes

\begin{tabular}{|c|c|c|c|c|c|c|c|c|}
\hline & (1) & $(2)$ & $(3)$ & $(4)$ & $(5)$ & $(6)$ & $(7)$ & $(8)$ \\
\hline $\mathrm{T}$ & $\begin{array}{c}0.000 \\
(0.055)\end{array}$ & $\begin{array}{c}0.000 \\
(0.055)\end{array}$ & $\begin{array}{l}-0.007 \\
(0.050)\end{array}$ & $\begin{array}{c}0.001 \\
(0.055)\end{array}$ & $\begin{array}{c}0.002 \\
(0.055)\end{array}$ & $\begin{array}{l}-0.003 \\
(0.053)\end{array}$ & $\begin{array}{l}-0.004 \\
(0.050)\end{array}$ & $\begin{array}{c}0.017 \\
(0.062)\end{array}$ \\
\hline $\mathrm{T} \times \mathrm{CR}$ & & $\begin{array}{l}-0.036 \\
(0.045)\end{array}$ & & & & & $\begin{array}{l}-0.010 \\
(0.042)\end{array}$ & $\begin{array}{c}0.016 \\
(0.042)\end{array}$ \\
\hline $\mathrm{T} \times \mathrm{ES}$ & & & $\begin{array}{c}-0.149^{* * *} \\
(0.050)\end{array}$ & & & & $\begin{array}{c}-0.172^{* * *} \\
(0.045)\end{array}$ & $\begin{array}{c}-0.181^{* * *} \\
(0.056)\end{array}$ \\
\hline $\mathrm{T} \times \mathrm{SS}$ & & & & $\begin{array}{c}0.012 \\
(0.056)\end{array}$ & & & $\begin{array}{c}0.037 \\
(0.048)\end{array}$ & $\begin{array}{c}0.057 \\
(0.052)\end{array}$ \\
\hline $\mathrm{T} \times \mathrm{WS}$ & & & & & $\begin{array}{c}0.039 \\
(0.040)\end{array}$ & & $\begin{array}{c}0.071^{* *} \\
(0.036)\end{array}$ & $\begin{array}{c}0.109^{* * *} \\
(0.039)\end{array}$ \\
\hline $\mathrm{T} \times$ MIIS & & & & & & $\begin{array}{l}0.087^{*} \\
(0.046)\end{array}$ & $\begin{array}{l}-0.010 \\
(0.043)\end{array}$ & $\begin{array}{l}-0.016 \\
(0.044)\end{array}$ \\
\hline Year FE & $x$ & $x$ & $x$ & $x$ & $x$ & $x$ & $x$ & $x$ \\
\hline Building FE & $\times$ & $\times$ & $\times$ & $\times$ & $x$ & $\times$ & $\times$ & $\times$ \\
\hline Adj. R-square & 0.677 & 0.678 & 0.681 & 0.677 & 0.678 & 0.679 & 0.682 & 0.565 \\
\hline Observations & 9,728 & 9,728 & 9,728 & 9,728 & 9,728 & 9,728 & 9,728 & 7,070 \\
\hline
\end{tabular}

Notes: This table reports estimates of energy savings from the LEED program in federal buildings over the period 1990-2019, and the results of the heterogeneity analysis regarding different program attributes. The dependent variable is the log of site energy use intensity, and the untreated group is constructed using five-nearest-neighbor $(5 \mathrm{NN})$ matching with replacement. Energy use intensity is defined as the ratio of total energy consumption and the square footage of a building. Site energy is the amount of heat and electricity consumed by a building as reflected in the utility bill. $\mathrm{T}$ is the treatment indicator equal to one if a building $i$ in year $t$ is certified, and zero otherwise. CR stands for certified ratio, and refers to the fraction of a building square footage that is LEED-certified. ES, SS, WS, and MIIS represent the component scores evaluated by the LEED program: energy and atmosphere, sustainable sites, water efficiency, and the combination of material, indoor environment, and innovation, respectively. To facilitate comparison, CR, ES, SS, WS, and MIIS are all standardized to have mean zero and standard deviation one. Column (1) reports the aggregate energy savings from the LEED program. Columns (2)-(6) differentiate the energy savings by each attribute of the LEED program. Columns (7) and (8) show estimates when including all program attributes in the regression. Column (7) reports the results for all buildings, and column (8) restricts attention to office buildings. The coefficients on LEED certification in columns (1)-(8) are consistently small and insignificant, which suggest that LEED certification did not have a statistically significant effect on energy consumption. A significant negative estimate on energy component score, and a significant positive estimate on water component score after controlling for the rest of the attributes in the LEED program in columns (7) and (8) suggest a trade-off between energy and water components when a building is LEED certified. CDD and HDD are included as controls in all regressions. Because of the potentially repeated non-LEED buildings in the untreated group due to matching with replacement, all regressions are weighted by the inverse of the number of repeated observations. Standard errors clustered by building are reported in parentheses. ${ }^{* * *}$ denotes statistical significance at the $1 \%$ level, ${ }^{* *}$ at the $5 \%$ level, and * at the $10 \%$ level. 
Table 3: Energy Use Intensity Impacts from Different Dimensions of the LEED Program with Controls for Other Energy Conservation Programs

\begin{tabular}{|c|c|c|c|c|}
\hline & \multicolumn{2}{|c|}{ "With Upgrades } & \multicolumn{2}{|c|}{ 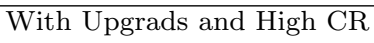 } \\
\hline & $(1)$ & $(2)$ & $(3)$ & $(4)$ \\
\hline $\bar{T}$ & $\begin{array}{l}-0.002 \\
(0.050)\end{array}$ & $\begin{array}{c}0.010 \\
(0.061)\end{array}$ & $\begin{array}{l}-0.008 \\
(0.053)\end{array}$ & $\begin{array}{c}0.029 \\
(0.062)\end{array}$ \\
\hline $\mathrm{T} \times \mathrm{CR}$ & $\begin{array}{l}-0.016 \\
(0.043)\end{array}$ & $\begin{array}{c}0.006 \\
(0.042)\end{array}$ & $\begin{array}{l}-0.030 \\
(0.056)\end{array}$ & $\begin{array}{l}-0.026 \\
(0.060)\end{array}$ \\
\hline $\mathrm{T} \times \mathrm{ES}$ & $\begin{array}{c}-0.172^{* * *} \\
(0.045)\end{array}$ & $\begin{array}{c}-0.173^{* * *} \\
(0.055)\end{array}$ & $\begin{array}{c}-0.200^{* * *} \\
(0.041)\end{array}$ & $\begin{array}{c}-0.218^{* * *} \\
(0.054)\end{array}$ \\
\hline $\mathrm{T} \times \mathrm{SS}$ & $\begin{array}{c}0.027 \\
(0.042)\end{array}$ & $\begin{array}{c}0.037 \\
(0.041)\end{array}$ & $\begin{array}{c}0.005 \\
(0.049)\end{array}$ & $\begin{array}{c}0.025 \\
(0.049)\end{array}$ \\
\hline $\mathrm{T} \times \mathrm{WS}$ & $\begin{array}{c}0.074^{* *} \\
(0.036)\end{array}$ & $\begin{array}{c}0.113^{* * *} \\
(0.041)\end{array}$ & $\begin{array}{c}0.060 \\
(0.038)\end{array}$ & $\begin{array}{c}0.080^{* *} \\
(0.040)\end{array}$ \\
\hline $\mathrm{T} \times \mathrm{MIIS}$ & $\begin{array}{l}-0.013 \\
(0.042)\end{array}$ & $\begin{array}{l}-0.010 \\
(0.042)\end{array}$ & $\begin{array}{l}-0.038 \\
(0.054)\end{array}$ & $\begin{array}{l}-0.044 \\
(0.048)\end{array}$ \\
\hline Advanced Metering & $\begin{array}{c}0.082^{* *} \\
(0.036)\end{array}$ & $\begin{array}{c}0.120^{* * *} \\
(0.041)\end{array}$ & $\begin{array}{c}0.093^{* *} \\
(0.037)\end{array}$ & $\begin{array}{c}0.131^{* * *} \\
(0.044)\end{array}$ \\
\hline Building Envelope & $\begin{array}{l}-0.008 \\
(0.038)\end{array}$ & $\begin{array}{l}-0.008 \\
(0.046)\end{array}$ & $\begin{array}{c}0.008 \\
(0.038)\end{array}$ & $\begin{array}{c}0.017 \\
(0.047)\end{array}$ \\
\hline Utility Improvement & $\begin{array}{c}0.007 \\
(0.038)\end{array}$ & $\begin{array}{l}-0.044 \\
(0.042)\end{array}$ & $\begin{array}{c}0.004 \\
(0.038)\end{array}$ & $\begin{array}{l}-0.053 \\
(0.043)\end{array}$ \\
\hline HVAC & $\begin{array}{l}-0.012 \\
(0.037)\end{array}$ & $\begin{array}{l}-0.040 \\
(0.043)\end{array}$ & $\begin{array}{l}-0.007 \\
(0.037)\end{array}$ & $\begin{array}{l}-0.028 \\
(0.043)\end{array}$ \\
\hline Indoor Environmental Quality & $\begin{array}{l}-0.046 \\
(0.041)\end{array}$ & $\begin{array}{l}-0.040 \\
(0.045)\end{array}$ & $\begin{array}{l}-0.041 \\
(0.042)\end{array}$ & $\begin{array}{l}-0.038 \\
(0.047)\end{array}$ \\
\hline Lighting & $\begin{array}{l}-0.027 \\
(0.032)\end{array}$ & $\begin{array}{c}0.009 \\
(0.040)\end{array}$ & $\begin{array}{l}-0.031 \\
(0.032)\end{array}$ & $\begin{array}{l}-0.001 \\
(0.040)\end{array}$ \\
\hline Renewable & $\begin{array}{l}-0.021 \\
(0.056)\end{array}$ & $\begin{array}{c}0.005 \\
(0.057)\end{array}$ & $\begin{array}{c}-0.024 \\
(0.060)\end{array}$ & $\begin{array}{l}-0.005 \\
(0.061)\end{array}$ \\
\hline Water & $\begin{array}{c}0.045 \\
(0.047)\end{array}$ & $\begin{array}{c}0.036 \\
(0.051)\end{array}$ & $\begin{array}{c}0.063 \\
(0.046)\end{array}$ & $\begin{array}{c}0.058 \\
(0.051)\end{array}$ \\
\hline Other & $\begin{array}{c}0.144 \\
(0.102)\end{array}$ & $\begin{array}{l}0.265^{*} \\
(0.147)\end{array}$ & $\begin{array}{c}0.160 \\
(0.103)\end{array}$ & $\begin{array}{l}0.277^{*} \\
(0.145)\end{array}$ \\
\hline Year FE & $\times$ & $\times$ & $\times$ & $\times$ \\
\hline Building FE & $\times$ & $x$ & $\times$ & $x$ \\
\hline Adj. R-square & 0.683 & 0.568 & 0.681 & 0.557 \\
\hline Observations & 9,728 & 7,070 & 9,520 & 6,890 \\
\hline
\end{tabular}

Notes: This table reports results from several robustness checks. T is the treatment indicator equal to one if a building $i$ in year $t$ is LEED-certified, and zero otherwise. CR stands for certified ratio, and refers to the fraction of a building square footage that is LEED-certified. ES, SS, WS, and MIIS represent the component scores evaluated by the LEED program: energy and atmosphere, sustainable sites, water efficiency, and the combination of material, indoor environment, and innovation, respectively. To facilitate comparison, CR, ES, SS, WS, and MIIS are all standardized to have mean zero and standard deviation one. Columns (1) and (2) re-estimate the specifications of the last columns of Table 2 with the inclusion of controls for other energy conservation upgrades. Each control variable is equal to one if a building $i$ in year $t$ has completed the upgrade. Columns (3) and (4) further restrict the sample to eliminate LEED buildings with low certified ratios. Seven LEED buildings with certified ratios below $50 \%$ are dropped in these two columns. The dependent variable is the log of site energy use intensity, and the untreated group is constructed using five-nearest-neighbor (5NN) matching with replacement. Columns (1) and (3) include all federal buildings, and columns (2) and (4) include office buildings only. Comparing to the main results in Table 2, the estimates for different attributes of the LEED program are similar. CDD and HDD are included as controls in all regressions. Because of the potentially repeated non-LEED buildings in the untreated group due to matching with replacement, all regressions are weighted by the inverse of the number of repeated observations. Standard errors clustered by building are reported in parentheses. ${ }^{* * *}$ denotes statistical significance at the $1 \%$ level, ${ }^{* *}$ at the $5 \%$ level, and $*$ at the $10 \%$ level. 


\section{Online Appendix (Not For Publication)}

\section{"Does LEED Certification Save Energy? \\ Evidence from Federal Buildings"}

Karen Clay, Edson Severnini, and Xiaochen Sun*

\footnotetext{
*Karen Clay, Edson Severnini, and Xiaochen Sun: H. John Heinz III College, Carnegie Mellon University, 4800 Forbes Avenue, Pittsburgh, PA 15213. Emails: kclay@andrew.cmu.edu, edsons@andrew.cmu.edu, and xiaoches@andrew.cmu.edu.
} 


\section{Appendix I: LEED Program Introduction}

LEED was first developed and launched by USGBC with the help from the Federal Energy Management Program in 1998 (Rosa, 2016). Unlike other widely recognized labels such as Energy Star, which focus energy use, LEED certifies a building based on a comprehensive evaluation of six categories. When the total score of these categories exceeds a certain range, the building is LEED certified.

There are several LEED programs involved in our dataset (Appendix Table A.3), yet more than half of them were certified with LEED EB 2009. The LEED scoreboard generally includes energy and atmosphere, materials and resources, indoor environmental quality, sustainable sites, water efficiency, and innovation in operations. With each of them taking up different proportions of the total score, the energy component accounts for the largest share, more than 30\%. ${ }^{1}$ Appendix Table A.1 sketches some main credit categories for different components with examples. Some upgrades in the non-energy component might results in higher energy consumption. For example, water saving faucets with sensors might consume more energy compared to those without.

\footnotetext{
${ }^{1}$ There could be minimum score requirement for some components, but the mandatory score is small in comparison to the maximum score of the components.
} 


\section{Appendix II: Robustness Check on Non-LEED Build-}

\section{ings}

The energy savings are derived by comparing the difference in consumption between LEED and non-LEED buildings in post certification period relative to the same difference before the reference year. Although we implemented the propensity score matching, it would still be a concern if the untreated buildings are affected by some shocks that are missed from the difference-in-differences model but would drive down their energy use intensity.

We repeat the first and second stage regressions with only the non-LEED buildings and report the $\delta$ 's from equation (3). We follow the step below to first assign the treatment indicator to the untreated buildings:

1. Generate bins based on the building size with bandwidth of $7,500 \mathrm{ft}^{2}$.

2. If the non-LEED buildings fall into the same bin with a LEED building, those non-LEED buildings are assigned the treatment date of this LEED building.

3. If two or more LEED building appear in the same bin, we generate random numbers for both LEED and non-LEED buildings in the bin. Then, we assign the treatment date of the LEED buildings to the non-LEED buildings if their numbers match.

4. If a non-LEED building lays in a bin that does not contain any LEED buildings, this non-LEED building will not be assigned to any treatment date and is regarded as untreated.

Take the sample after 5NN matching as an example. Among the 300 non-LEED buildings, 105 of them are assigned as treated while all the rest as assigned as untreated. Then, we follow the steps similar to the main results estimation and construct a balanced panel for the treated buildings to ensure enough pre- and post- treatment periods. This process eliminates 9 buildings from the treated group and leaves us with 96 buildings. ${ }^{2}$ We then apply the same specification as the main results for the propensity score matching and the event study regression.

\footnotetext{
${ }^{2}$ Because there are repeated buildings in the non-LEED buildings group from the with replacement propensity score matching stage, the number of buildings identified in the text does not correspond to the amount of unique buildings. Among the 9 eliminated buildings, 4 buildings are unique.
} 
Figure $2 \mathrm{~b}$ plots the results of the second stage using non-LEED buildings after $5 \mathrm{NN}$ matching. All the $\delta$ 's are around zero in the figure, which suggest that there is no shocks in the non-LEED buildings. We also conduct the robustness checks for the sample after $3 \mathrm{NN}$ matching and observe similar zero $\delta$ 's for all event times (see Appendix Figure A.10). 


\section{Appendix III: Figures and Tables}

Figure A.1: The Distribution of the Certified Ratio in the Treated Group

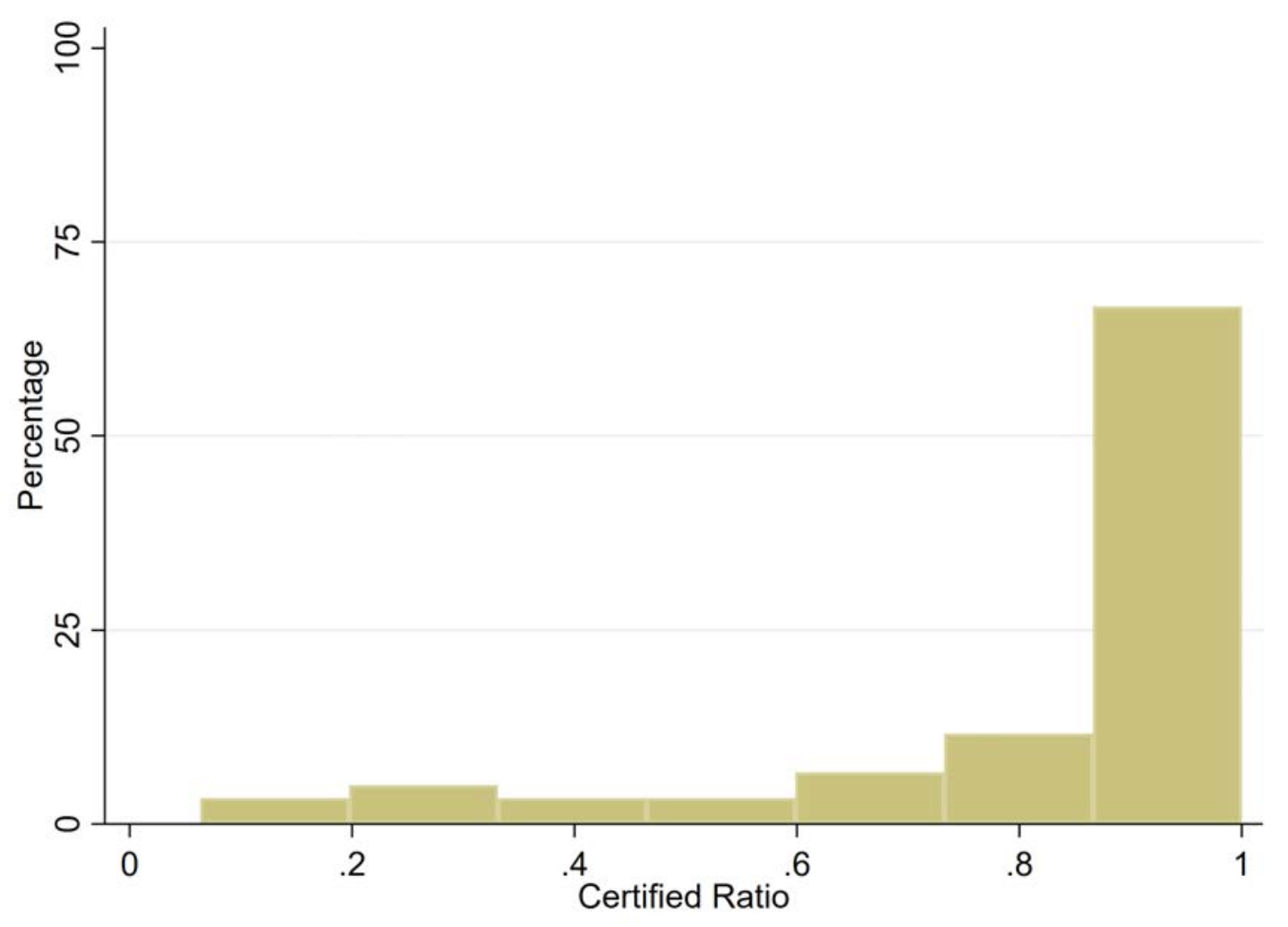

Notes: This figure shows the distribution of certified ratio in the LEED buildings. Note that we regard a building as certified unless the ratio is greater than $5 \%$. Thus, the start point of the first bin is 0.05 . The ratio average, 10th, 50th, and 90th percentile are $0.831,0.411,0.930$, and 1 . 
Figure A.2: The Distribution of the Component Score

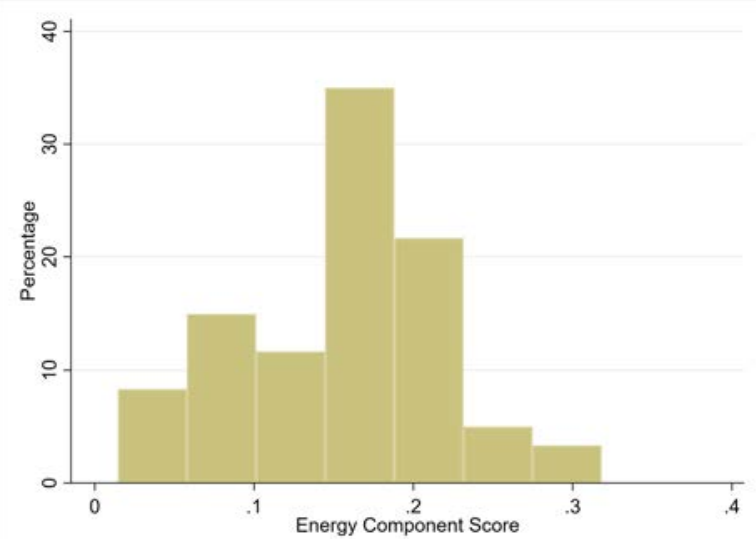

(a) Energy Component Score

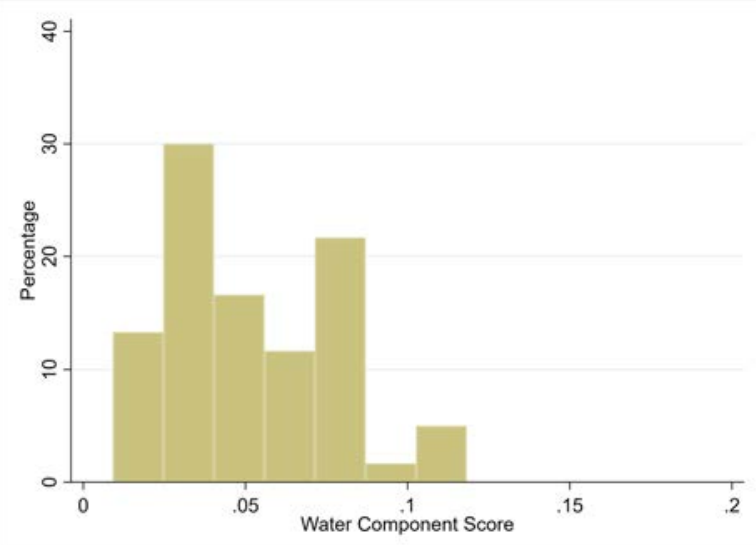

(c) Water Component Score

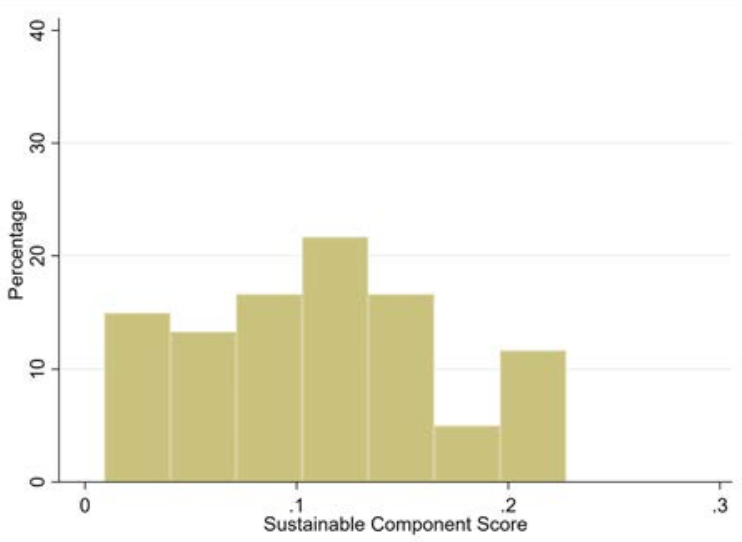

(b) Sustainable Component Score

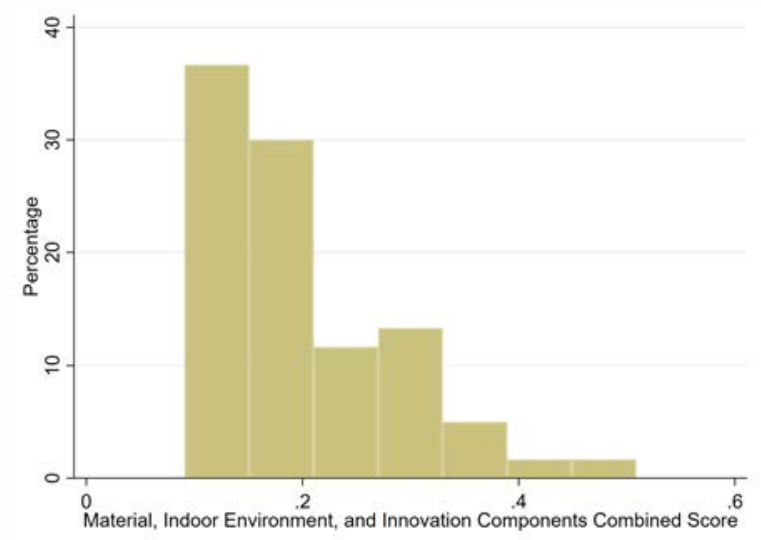

(d) Material, Indoor Environment, and Innovation Components Combined Score

Notes: This figure presents the distributions of the component scores in the LEED buildings. The energy, sustainable and water component scores spread out symmetrically. The material, indoor environment, and innovation components combined score is right skewed with most of the buildings fall in the first bin. The score average, 10th, 50th, and 90th percentile are $0.153,0.058,0.159$, and 0.227 for the energy component; $0.110,0.036,0.115$, and 0.200 for the sustainable component; $0.050,0.018,0.050$, and 0.082 for the water component; 0.193, $0.109,0.155$, and 0.297 for the material, indoor environment, and innovation components combined. 
Figure A.3: Locations of LEED and Non-LEED Buildings

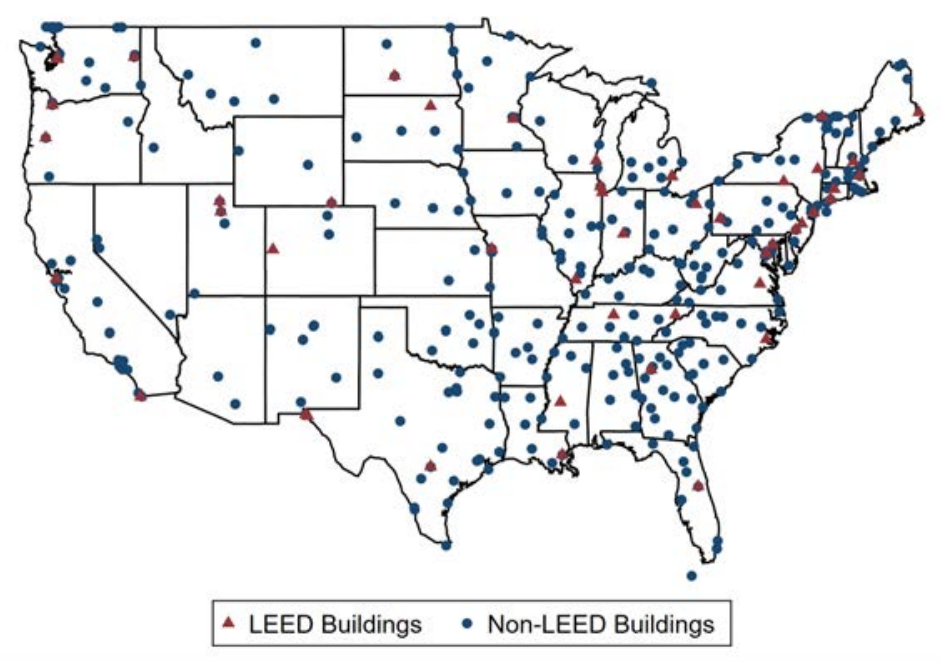

(a) Before Propensity Score Matching

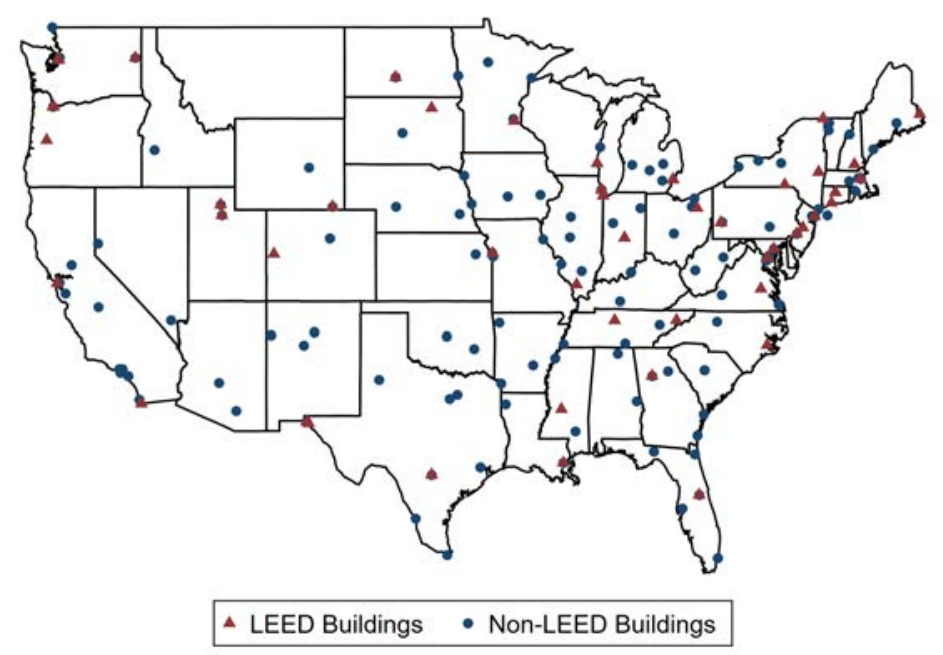

(b) After Propensity Score Matching

Notes: This figure plots the locations of the LEED and non-LEED buildings before and after the propensity score matching. (a) plots the location of buildings before matching; (b) shows the building locations after matching with $5 \mathrm{NN}$. 
Figure A.4: The Distribution of Average Energy Use Intensity (in Logarithm Form) Before and After the Certification

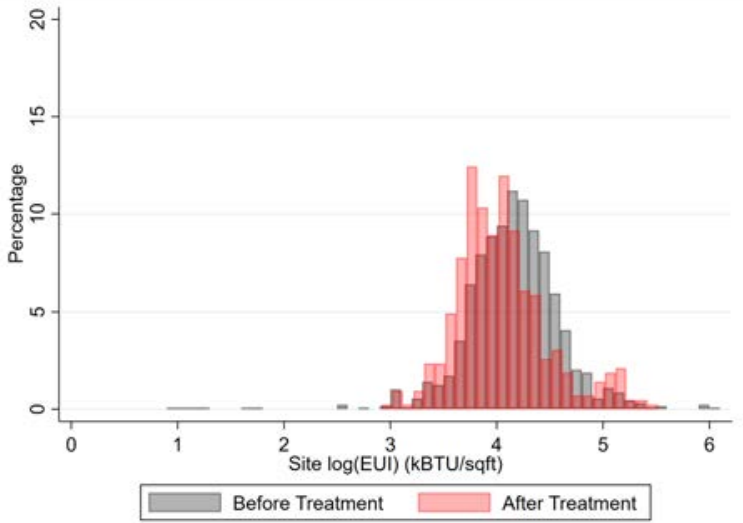

(a) LEED buildings

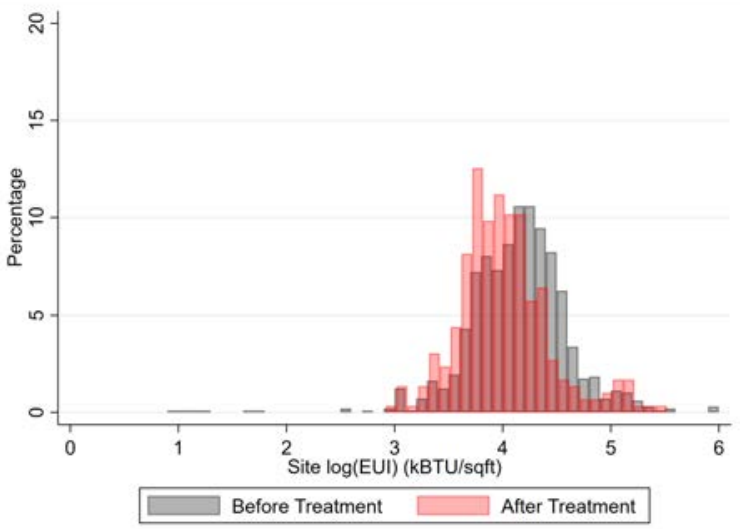

(c) LEED Office buildings

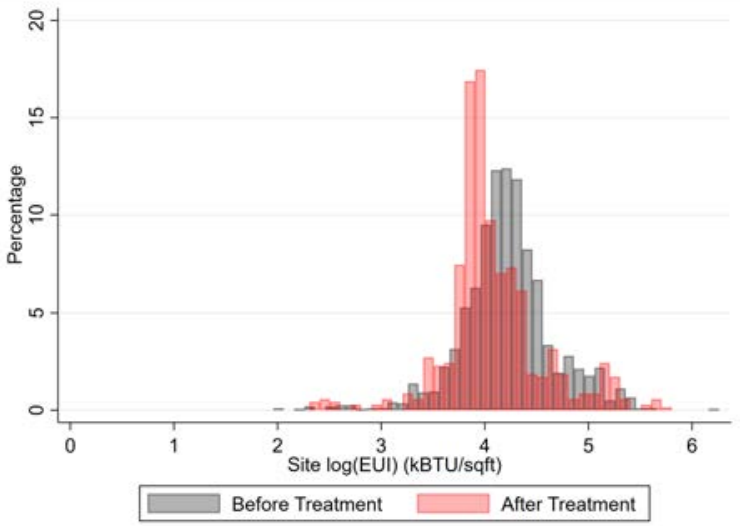

(b) Non-LEED buildings (Falsification Test)

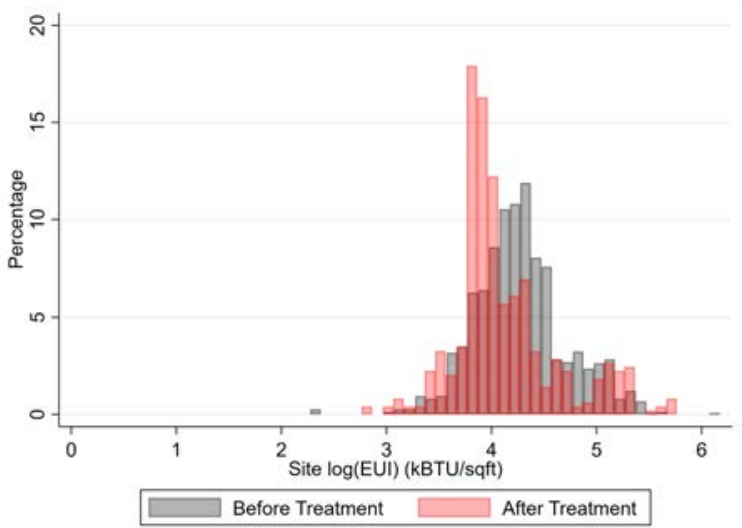

(d) Non-LEED Office buildings (Falsification Test)

Notes: This figure presents the distributions the average energy use intensity in LEED and non-LEED buildings. (a) plots the histogram of average energy use intensity in LEED buildings both before and after the certification. (b) follows the Falsification Test procedures (Appendix II), and depicts the histogram of average energy use intensity in non-LEED buildings before and after the assigned treatment date. Similarly, (c) and (d) are the histograms of LEED and non-LEED office buildings. 
Figure A.5: Difference in Energy Use Intensity between LEED and Non-LEED Buildings Over Years

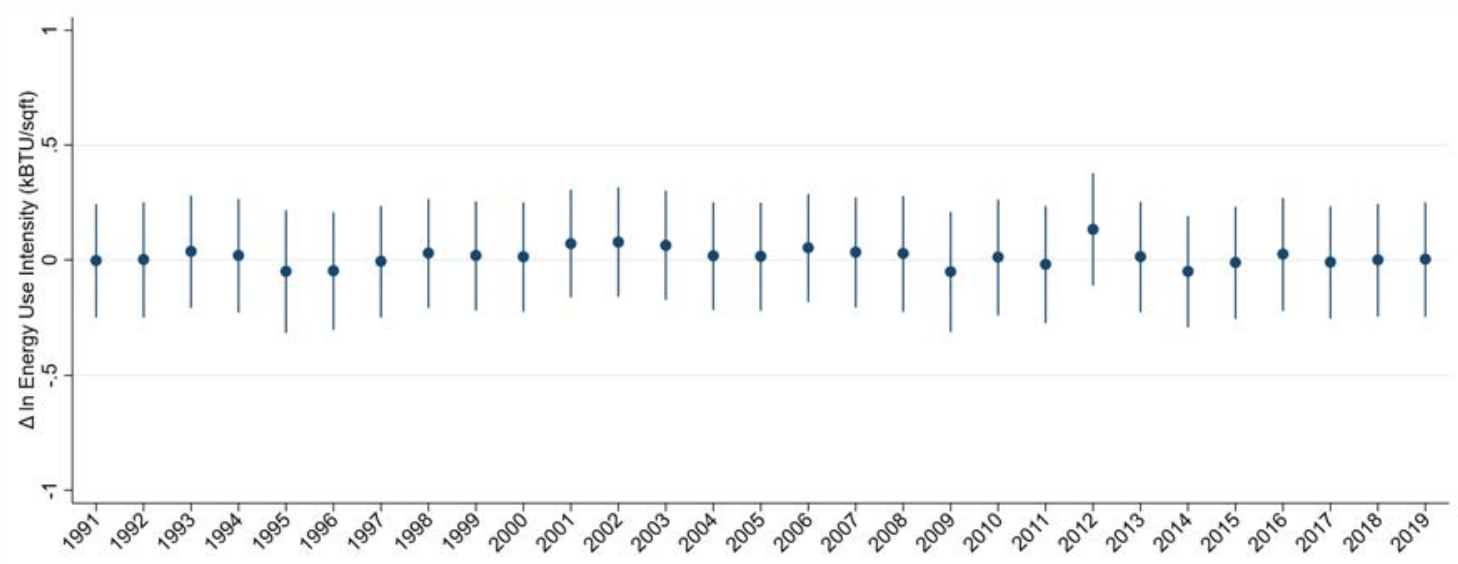

Notes: This figure displays the difference in energy use intensity between LEED and non-LEED buildings throughout years. The descriptive regression is specified as follows

$\ln \left(E U I_{i t}\right)=\sum_{\tau=1990}^{2019} \omega_{\tau}$ Year $_{t} \times L E E D_{i}+\sum_{\tau=1990}^{2019} \lambda_{\tau} Y_{\text {ear }}+\sum_{i=0}^{1} \xi_{i} L E E D_{i}+\sum_{\tau=1990}^{2019} \phi_{\tau} 1 s t Y e a r_{i t}+\epsilon_{i t}$

The dependent variable is the energy use intensity in logarithm form for each building $i$ in year $t$. Year $_{t}$ is a dummy variable that equals 1 when $t=\tau$ and equals 0 otherwise. $L E E D_{i}$ is also an indicator variable and equals to 1 if building $i$ is certified and 0 otherwise. 1 stYear ${ }_{i t}$ controls the noise brought about by the composition difference between the LEED and non-LEED buildings in the dataset. It equals to 1 if building $i$ first enters the dataset in year $t$. In another words, the last three sums serve as the year, LEED, and initial consumption composition fixed effects. The figure plots the all the $\omega_{\tau}$ 's to show the changes in energy consumption between treated and untreated groups from 1991 to 2019. Year 1990 is omitted because it is set as the reference year. As can be observed from the trend, the consumption difference between the two groups are similar and close to zero throughout years. 
Figure A.6: Completion Year of the First Energy Conservation Program for LEED and Non-LEED Buildings

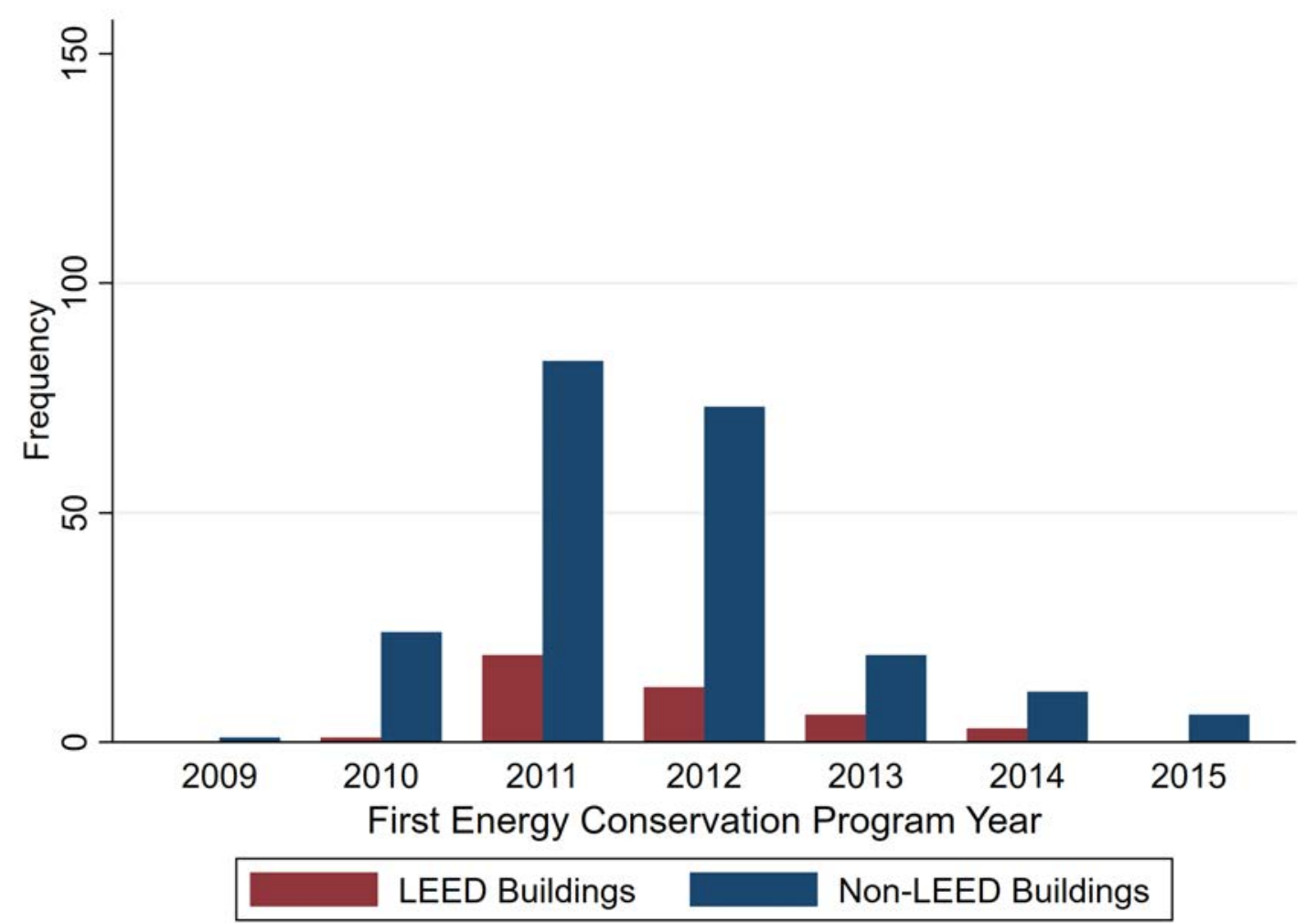

Notes: This figure is the bar plot of the completion year of the first energy conservation program in LEED and non-LEED buildings after 5NN matching. As indicated, most of the efficiency upgrade finished around 2011 and 2012. 
Figure A.7: The Distribution of the Completion Year Differences of the Energy

Conservation Upgrade and LEED Certification

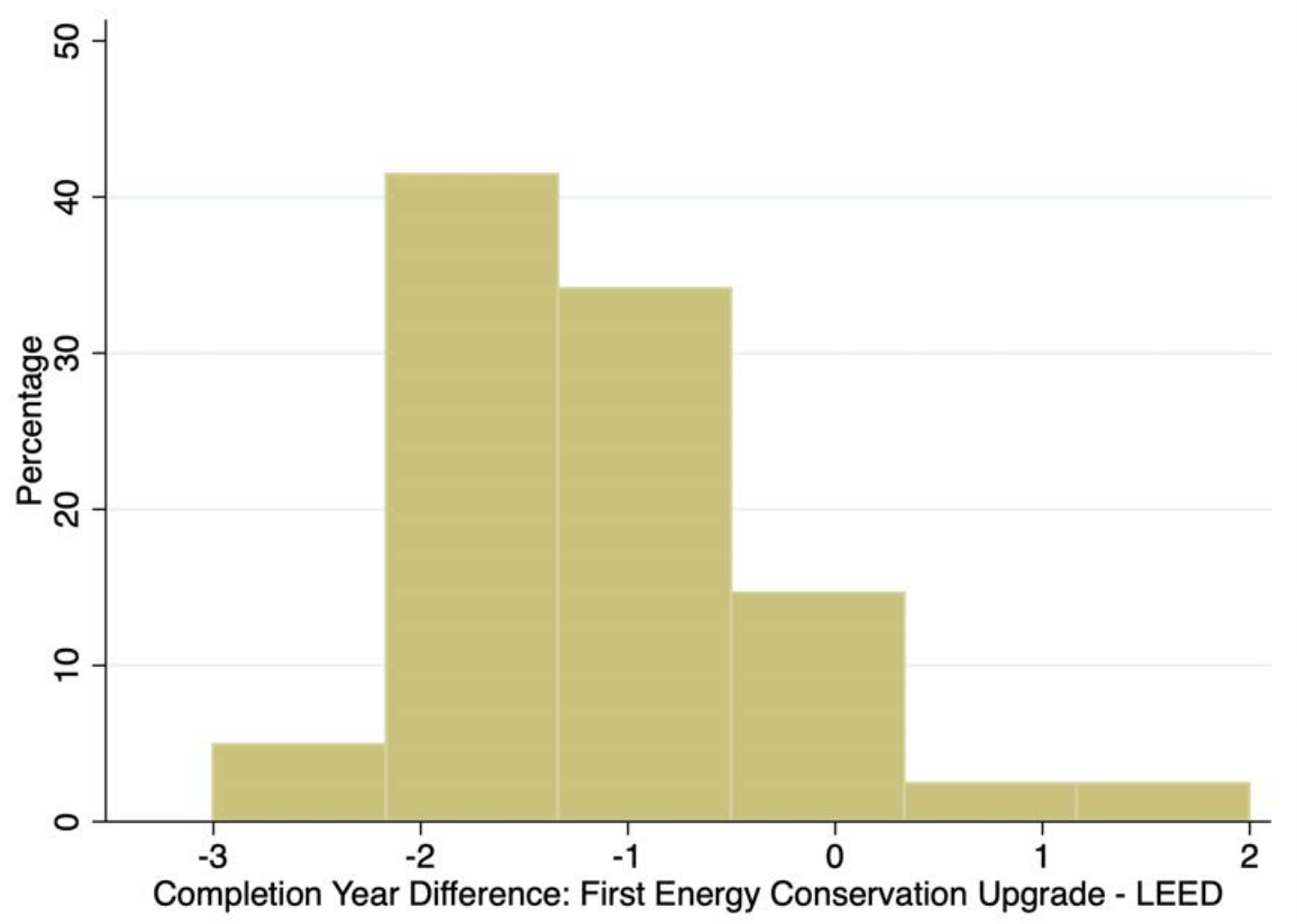

Notes: This figure provides the distribution of the completion year differences of the energy conservation upgrade and the LEED program. For example, -2 means the first energy conservation upgrade in the building was completed 2 years before the building was LEED certified. Among the 60 LEED certified buildings, 41 of them have adopted at least one energy conservation upgrade. This figure is plotted with these 41 LEED buildings. 
Figure A.8: Energy and Water Component Score Distribution Across Regions

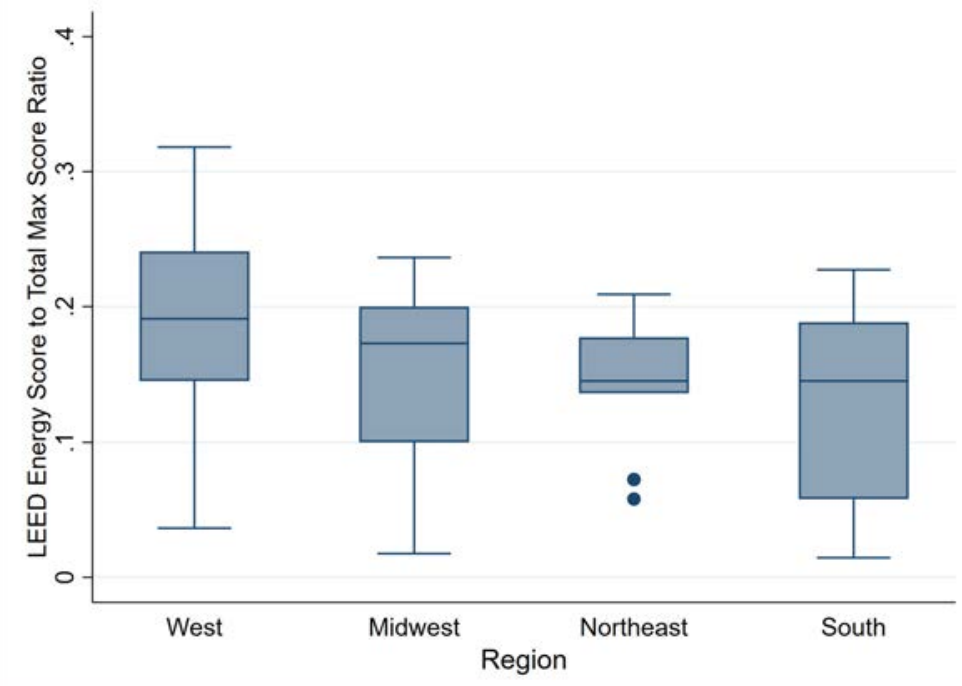

(a) Energy Component Score

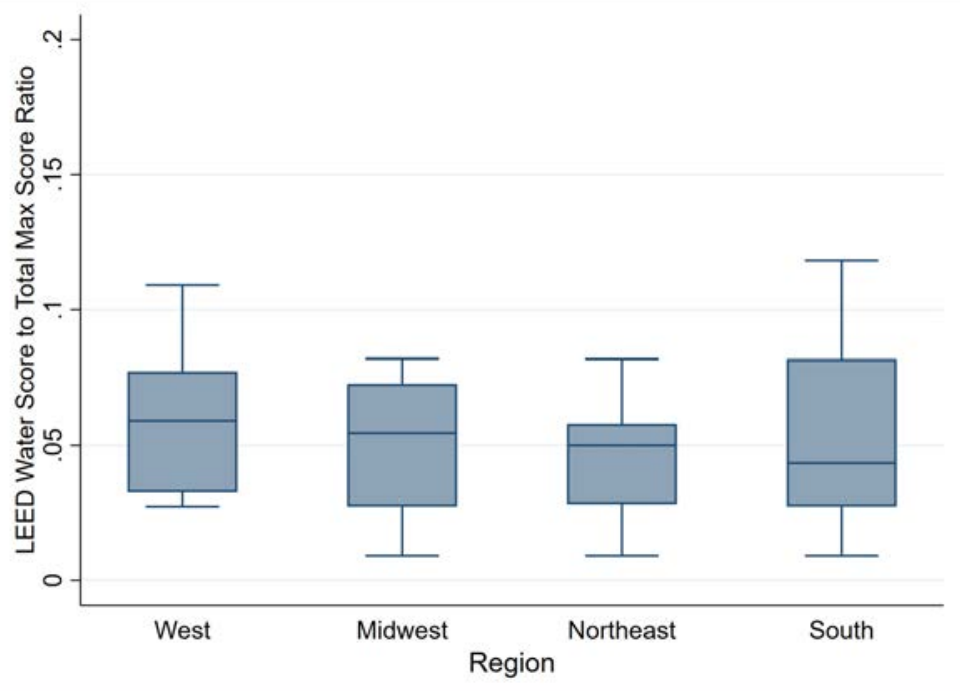

(b) Water Component Score

Notes: This figure provides energy and water component score distributions across the four census regions in the United States. Surprisingly, the score distributions are relatively similar across all four regions. 
Figure A.9: Energy Savings in Each Period Relative to the Reference Year Savings (Different Combinations of Energy Sources and Matching Procedures)

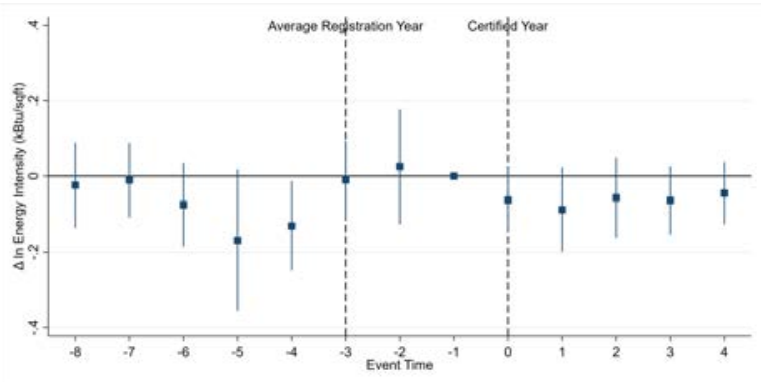

(a) Site EUI with $5 \mathrm{NN}$

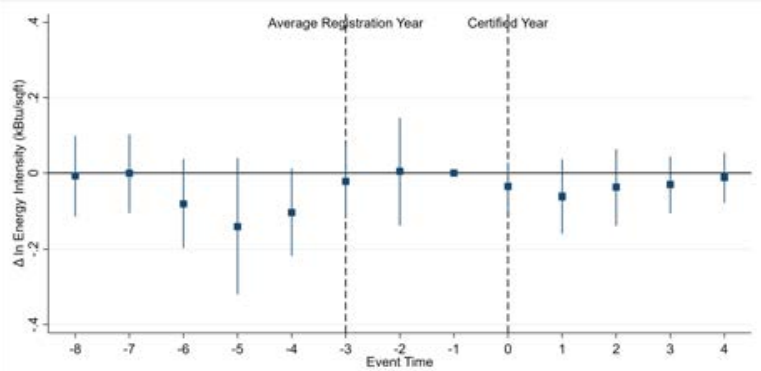

(c) Source EUI with 5NN

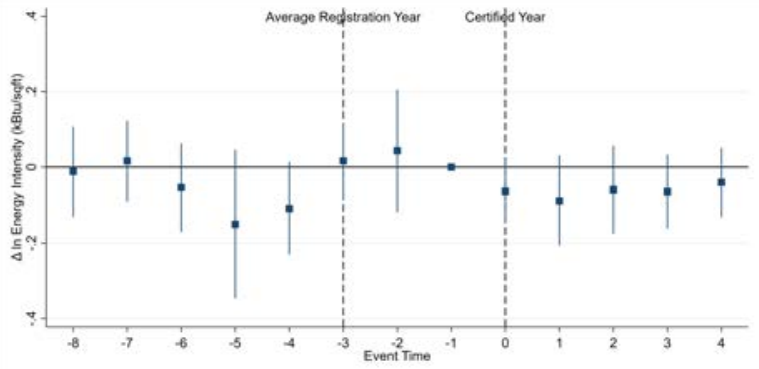

(b) Site EUI with 3NN

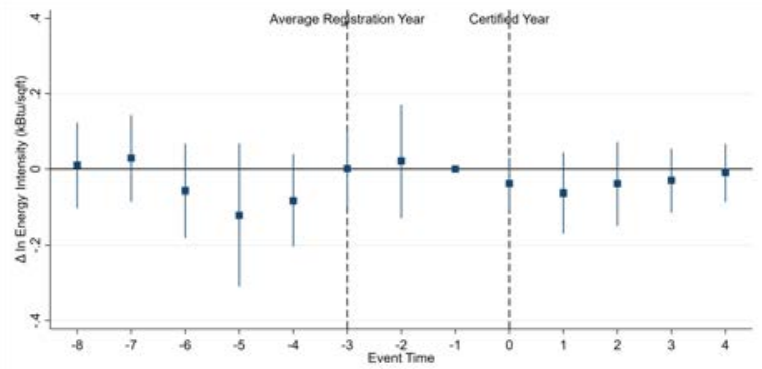

(d) Source EUI with $3 \mathrm{NN}$

Notes: This figure plots the $\delta$ 's from the event study regression in Equation (3). The reference year is set to be one year prior to the certification date. (a) and (b) use the site energy use intensity as the dependent variable and report the regression coefficients after the propensity score matching with $5 \mathrm{NN}$ and $3 \mathrm{NN}$. (c) and (d) plot the coefficients with source energy use intensity as the outcome variable. The vertical bars around the coefficients indicate the $95 \%$ confidence interval. 
Figure A.10: Energy Savings in Each Period Relative to the Reference Year Savings for the Untreated Buildings Only

(Falsification Test)

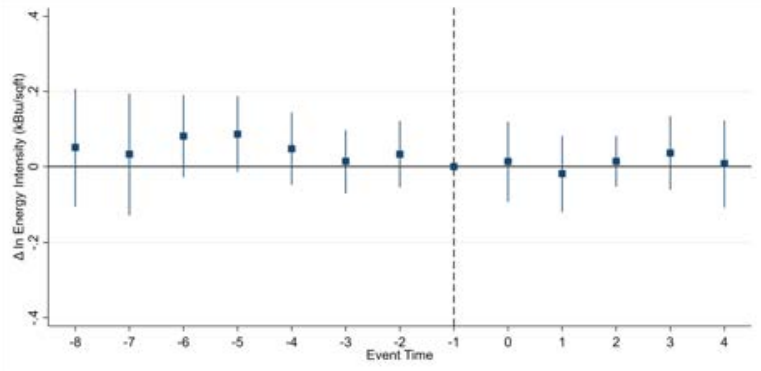

(a) Site EUI with $5 \mathrm{NN}$

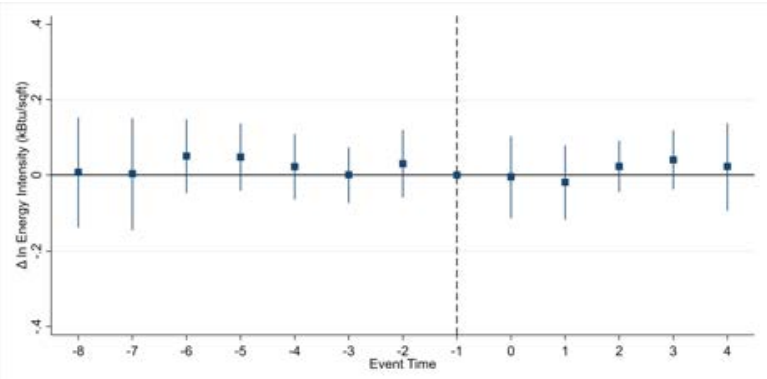

(c) Source EUI with $5 \mathrm{NN}$

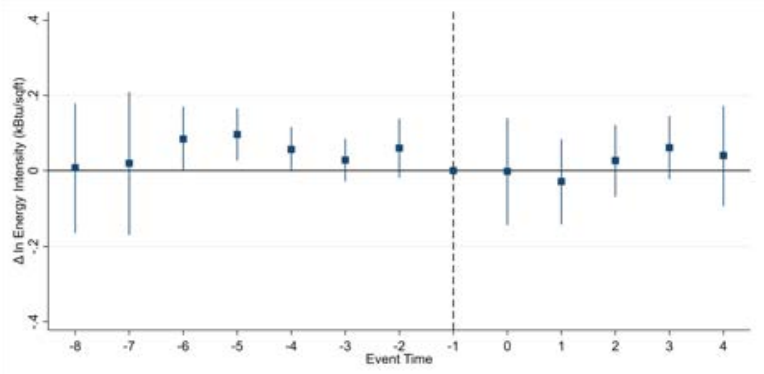

(b) Site EUI with 3NN

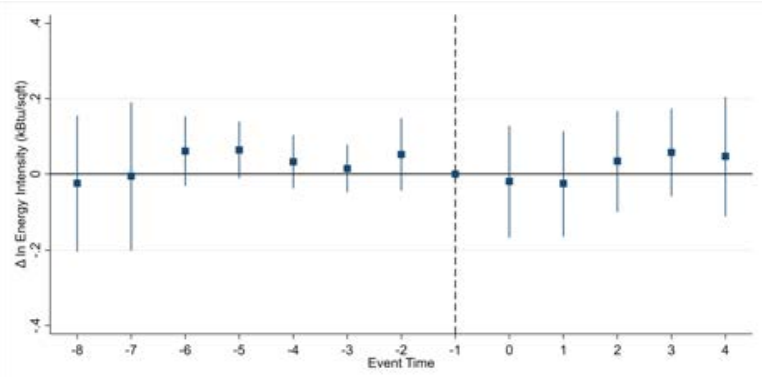

(d) Source EUI with 3NN

Notes: This figure provides robustness checks for the difference in differences approach. They repeat the exercise in Figure A.9 with the untreated buildings only. The untreated building sample is constructed following the procedures in Appendix II. The reference year is set to be one year prior to the certification date. (a) and (b) use the site energy use intensity as the dependent variable and report the regression coefficients after $5 \mathrm{NN}$ and $3 \mathrm{NN}$ propensity score matching. (c) and (d) use source energy use intensity as the outcome variable. The vertical bars around the coefficients indicate the $95 \%$ confidence interval. 
Table A.1: LEED Component Credit Category

\begin{tabular}{|c|c|c|c|}
\hline Score Components & Major Credit Categories & Points & Examples \\
\hline \multirow[t]{3}{*}{ Energy and Atmosphere } & Optimize Energy Performance & 18 & $\begin{array}{l}\text { High efficiency lighting with daylight- } \\
\text { ing controls, high efficiency HVAC, } \\
\text { high performance glazing and slab } \\
\text { insulation }\end{array}$ \\
\hline & Renewable Energy & 6 & Green power \\
\hline & Building Commissioning & 4 & Energy audit \\
\hline Sustainable Sites & $\begin{array}{l}\text { Alternative Commuting Op- } \\
\text { tions }\end{array}$ & 15 & Public bus lines, campus shuttle buses \\
\hline \multirow[t]{2}{*}{ Water Efficiency } & Indoor Fixture Efficiency & 5 & $\begin{array}{l}\text { Water saving sink faucets, WaterSense } \\
\text { certified automatic flush }\end{array}$ \\
\hline & Water Efficient Landscaping & 5 & High efficiency irrigation technology \\
\hline \multirow[t]{2}{*}{ Material and Resources } & Sustainable Purchasing & 6 & $\begin{array}{l}\text { Sustainable furniture, reduced mer- } \\
\text { cury in lamps, bathroom hand dryers }\end{array}$ \\
\hline & Solid Waste Management & 4 & Recycled materials, waste stream audit \\
\hline \multirow[t]{2}{*}{ Indoor Environmental Quality } & Green Cleaning & 6 & $\begin{array}{l}\text { Sustainable cleaning products and } \\
\text { materials }\end{array}$ \\
\hline & $\begin{array}{l}\text { Indoor Air Quality Best Man- } \\
\text { agement Practices }\end{array}$ & 5 & Effective ventilation, filter installation \\
\hline \multirow[t]{2}{*}{ Innovation in Operations } & Innovation in Operations & 4 & $\begin{array}{l}\text { Innovations on top of LEED } \\
\text { requirements }\end{array}$ \\
\hline & $\begin{array}{l}\text { LEED Accredited } \quad \text { Profes- } \\
\text { sional }\end{array}$ & 1 & Hire a LEED AP \\
\hline
\end{tabular}

Notes: This table provides an overview of some important credit categories for each component in the LEED score board using LEED EB 2009 as an example. LEED EB means LEED for existing buildings. More than half of the treated buildings included in our sample were certified based on LEED EB 2009. Note that the credit categories listed here are only the ones that contain the majority of points. The total achievable score for LEED EB 2009 is 110, with 35 points for Energy and Atmosphere, 26 points for Sustainable Sites, 14 points for Water Efficiency, 10 points for Material and Resources, 15 points for Indoor Environmental Quality, 6 points for Innovation in Operations, and 4 points for Regional Priority. Our paper does not include the discussion of Regional Priority because it grants points based on local issues, thus its requirements vary across different LEED programs. GBIG reports do not record the points for this component either. 
Table A.2: Summary of Sample Construction Criteria (Number of Unique Buildings)

\begin{tabular}{lcc}
\hline \hline & All Buildings & LEED Buildings \\
\hline Unbalanced Panel (Raw Data) & 1,561 & 110 \\
Federal Owned Buildings Only & -995 & 0 \\
Balanced Panel & -43 & -43 \\
Balanced Panel with LEED Component Score & -7 & -7 \\
\hline Number of Buildings in the Main Results & 516 & 60 \\
\hline \hline
\end{tabular}

Notes: This table summarizes the changes in sample sizes with corresponding sample construction criteria. We have a total of 1,561 buildings in the dataset. As discussed in Section 3, the LEED buildings are identified based on their address in the EUAS dataset and the GBIG reports. 7 out of 110 LEED buildings record vague/inaccurate street address in the EUAS dataset, thus we manually map them to LEED buildings in the GBIG reports through Google Maps. As indicated in the table, all LEED buildings are owned by the GSA. The balanced panel ensures that the LEED buildings have data at least 8 years before and 4 years after the treatment. Among the 43 buildings that are deducted from the complete data to construct a balanced panel for the analysis, 39 of them do not contain at least 8 years of data before the treatment date, where most of them only start recording their consumption around the certification year. The remaining 4 buildings do not report enough post treatment data (no longer than 2 years after the treatment). Due to different types of the LEED program, 7 buildings do not report the complete six components scores. The main results in the paper are estimated using the sample of balanced panel with complete LEED scores. This sample consists of 60 LEED buildings and 456 non-LEED buildings. 8 out of 60 LEED buildings in the sample are certified more than once, and we assign their first compliance year as the treatment indicator in our analysis. For robustness check, estimates remain stable if we exclude those 8 buildings from the treatment group. Also, for the record, we exclude one LEED building from the dataset because it has abnormal consumption trend over the years. Results with the inclusion of this building are similar to the main analysis. 
Table A.3: Summary of Relevant LEED Programs in the Sample for Main Results

\begin{tabular}{lc}
\hline \hline & Number of LEED Buildings \\
\hline LEED NC 2.1 & 6 \\
LEED NC 2.2 & 5 \\
LEED NC 2009 & 9 \\
LEED EB 2009 & 34 \\
LEED CI 2.0 & 3 \\
LEED CI 2009 & 1 \\
LEED CS 2.0 & 1 \\
LEED CS 2009 & 1 \\
\hline Total Frequency & 60 \\
\hline \hline
\end{tabular}

Notes: This table presents the types of LEED programs involved in the main results estimation. Although multiple LEED programs are involved in the analysis, more than half of them are certified with LEED EB 2009. Glossary of the program abbreviations are: LEED NC (LEED for New Construction); LEED EB (LEED for Existing Buildings); LEED CI (LEED for Commercial Interiors); LEED CS (LEED for Core \& Shell). 
Table A.4: Correlation Matrix of Attributes in the LEED Program

\begin{tabular}{cccccccc}
\hline \hline & CR & ES & SS & IS & MS & WS & OS \\
\hline CR & 1.000 & & & & & & \\
ES & 0.124 & 1.000 & & & & & \\
SS & 0.008 & 0.148 & 1.000 & & & & \\
IS & -0.168 & -0.444 & 0.055 & 1.000 & & & \\
MS & -0.175 & -0.472 & 0.159 & 0.671 & 1.000 & & \\
WS & -0.078 & 0.186 & 0.072 & 0.018 & 0.028 & 1.000 & \\
OS & -0.253 & -0.428 & -0.019 & 0.490 & 0.493 & -0.021 & 1.000 \\
\hline \hline
\end{tabular}

Notes: This table presents the correlation matrix for different attributes in the LEED program. CR stands for certified ratio, and refers to the fraction of a building square footage that is LEED-certified. ES, SS, IS, MS, WS, and OS represent the component scores evaluated by the LEED program: energy and atmosphere, sustainable sites, indoor environmental quality, materials and resources, water efficiency, and innovation in operation, respectively. As observed, MS, IS, and OS, which are relatively highly correlated. 
Table A.5: Energy Use Intensity Outcome and Heterogeneity Analysis

(Different Combinations of Energy Sources and Matching Methods)

\begin{tabular}{|c|c|c|c|c|c|c|c|c|}
\hline & \multicolumn{4}{|c|}{ Site Energy } & \multicolumn{4}{|c|}{ Source Energy } \\
\hline & $\begin{array}{c}(1) \\
5 \mathrm{NN}\end{array}$ & $\begin{array}{c}(2) \\
5 \mathrm{NN}\end{array}$ & $\begin{array}{c}(3) \\
3 \mathrm{NN}\end{array}$ & $\begin{array}{c}(4) \\
3 \mathrm{NN}\end{array}$ & $\begin{array}{c}(5) \\
5 \mathrm{NN}\end{array}$ & $\begin{array}{c}(6) \\
5 \mathrm{NN}\end{array}$ & $\begin{array}{c}(7) \\
3 \mathrm{NN}\end{array}$ & $\begin{array}{c}(8) \\
3 \mathrm{NN}\end{array}$ \\
\hline $\mathrm{T}$ & $\begin{array}{l}-0.004 \\
(0.050)\end{array}$ & $\begin{array}{c}0.017 \\
(0.062)\end{array}$ & $\begin{array}{l}-0.011 \\
(0.049)\end{array}$ & $\begin{array}{c}0.018 \\
(0.061)\end{array}$ & $\begin{array}{l}-0.002 \\
(0.045)\end{array}$ & $\begin{array}{c}0.003 \\
(0.057)\end{array}$ & $\begin{array}{l}-0.016 \\
(0.045)\end{array}$ & $\begin{array}{l}-0.008 \\
(0.056)\end{array}$ \\
\hline $\mathrm{T} \times \mathrm{CR}$ & $\begin{array}{c}-0.010 \\
(0.042)\end{array}$ & $\begin{array}{c}0.016 \\
(0.042)\end{array}$ & $\begin{array}{l}-0.010 \\
(0.042)\end{array}$ & $\begin{array}{c}0.015 \\
(0.042)\end{array}$ & $\begin{array}{c}-0.021 \\
(0.041)\end{array}$ & $\begin{array}{c}-0.001 \\
(0.037)\end{array}$ & $\begin{array}{l}-0.021 \\
(0.041)\end{array}$ & $\begin{array}{l}-0.001 \\
(0.038)\end{array}$ \\
\hline $\mathrm{T} \times \mathrm{ES}$ & $\begin{array}{c}-0.172^{* * *} \\
(0.045)\end{array}$ & $\begin{array}{c}-0.181^{* * *} \\
(0.056)\end{array}$ & $\begin{array}{c}-0.173^{* * *} \\
(0.045)\end{array}$ & $\begin{array}{c}-0.181^{* * *} \\
(0.056)\end{array}$ & $\begin{array}{c}-0.158^{* * *} \\
(0.042)\end{array}$ & $\begin{array}{c}-0.141^{* * *} \\
(0.050)\end{array}$ & $\begin{array}{c}-0.158^{* * *} \\
(0.042)\end{array}$ & $\begin{array}{c}-0.142^{* * *} \\
(0.051)\end{array}$ \\
\hline $\mathrm{T} \times \mathrm{SS}$ & $\begin{array}{c}0.037 \\
(0.048)\end{array}$ & $\begin{array}{c}0.057 \\
(0.052)\end{array}$ & $\begin{array}{c}0.037 \\
(0.048)\end{array}$ & $\begin{array}{c}0.058 \\
(0.052)\end{array}$ & $\begin{array}{c}0.032 \\
(0.041)\end{array}$ & $\begin{array}{c}0.043 \\
(0.045)\end{array}$ & $\begin{array}{c}0.032 \\
(0.041)\end{array}$ & $\begin{array}{c}0.043 \\
(0.045)\end{array}$ \\
\hline $\mathrm{T} \times \mathrm{WS}$ & $\begin{array}{c}0.071^{* *} \\
(0.036)\end{array}$ & $\begin{array}{c}0.109^{* * *} \\
(0.039)\end{array}$ & $\begin{array}{l}0.071^{*} \\
(0.036)\end{array}$ & $\begin{array}{c}0.108^{* * *} \\
(0.039)\end{array}$ & $\begin{array}{c}0.056 \\
(0.034)\end{array}$ & $\begin{array}{c}0.095^{* *} \\
(0.037)\end{array}$ & $\begin{array}{c}0.056 \\
(0.034)\end{array}$ & $\begin{array}{c}0.095^{* *} \\
(0.037)\end{array}$ \\
\hline $\mathrm{T} \times \mathrm{MIIS}$ & $\begin{array}{c}-0.010 \\
(0.043) \\
\end{array}$ & $\begin{array}{l}-0.016 \\
(0.044) \\
\end{array}$ & $\begin{array}{c}-0.010 \\
(0.043) \\
\end{array}$ & $\begin{array}{l}-0.016 \\
(0.044) \\
\end{array}$ & $\begin{array}{c}-0.003 \\
(0.041) \\
\end{array}$ & $\begin{array}{l}-0.007 \\
(0.045) \\
\end{array}$ & $\begin{array}{c}-0.003 \\
(0.041)\end{array}$ & $\begin{array}{l}-0.006 \\
(0.046)\end{array}$ \\
\hline Year FE & $\times$ & $\times$ & $\times$ & $\times$ & $\times$ & $\times$ & $\times$ & $\times$ \\
\hline Building FE & $\times$ & $x$ & $x$ & $x$ & $\times$ & $x$ & $x$ & $\times$ \\
\hline Adj. R-square & 0.682 & 0.565 & 0.709 & 0.665 & 0.694 & 0.588 & 0.723 & 0.693 \\
\hline Observations & 9,728 & 7,070 & 6,461 & 4,433 & 9,728 & 7,070 & 6,461 & 4,433 \\
\hline
\end{tabular}

Notes: This table reports energy savings from the LEED program in federal buildings and the heterogeneity treatment effects regarding different program dimensions with different matching method and energy sources. The dependent variable is the log of site energy use intensity, and the untreated group is constructed using five-nearest-neighbor (5NN) and three-nearest-neighbor $(3 \mathrm{NN})$ matching with replacement. $\mathrm{T}$ is the treatment indicator equal to one if a building $i$ in year $t$ is certified, and zero otherwise. CR stands for certified ratio, and refers to the fraction of a building square footage that is LEED-certified. ES, SS, WS, and MIIS represent the component scores evaluated by the LEED program: energy and atmosphere, sustainable sites, water efficiency, and the combination of material, indoor environment, and innovation, respectively. To facilitate comparison, CR, ES, SS, WS, and MIIS are all standardized to have mean zero and standard deviation one. Column (1), (3), (5), and (7) are estimated regardless of building types, whereas column (2), (4), (6), and (8) restrict the sample to office buildings only. As observed, the coefficients are very similar to the main results reported in Table 2 column (7) and (8). CDD and HDD are included as controls in all regressions. Because of the potentially repeated non-LEED buildings in the untreated group due to matching with replacement, all regressions are weighted by the inverse of the number of repeated observations. Standard errors clustered by building are reported in parentheses. ${ }^{* * *}$ denotes statistical significance at the $1 \%$ level, ${ }^{* *}$ at the $5 \%$ level, and ${ }^{*}$ at the $10 \%$ level. 
Table A.6: Energy Use Intensity Outcome and Heterogeneity Analysis

(Monthly Data Regressions)

\begin{tabular}{|c|c|c|c|c|c|c|c|c|}
\hline & $(1)$ & $(2)$ & $(3)$ & $(4)$ & $(5)$ & $(6)$ & $(7)$ & $(8)$ \\
\hline $\mathrm{T}$ & $\begin{array}{l}-0.000 \\
(0.057)\end{array}$ & $\begin{array}{l}-0.001 \\
(0.056)\end{array}$ & $\begin{array}{l}-0.008 \\
(0.052)\end{array}$ & $\begin{array}{l}-0.000 \\
(0.057)\end{array}$ & $\begin{array}{c}0.001 \\
(0.057)\end{array}$ & $\begin{array}{l}-0.004 \\
(0.055)\end{array}$ & $\begin{array}{l}-0.006 \\
(0.051)\end{array}$ & $\begin{array}{c}0.007 \\
(0.064)\end{array}$ \\
\hline $\mathrm{T} \times \mathrm{CR}$ & & $\begin{array}{l}-0.043 \\
(0.046)\end{array}$ & & & & & $\begin{array}{l}-0.018 \\
(0.043)\end{array}$ & $\begin{array}{c}0.007 \\
(0.043)\end{array}$ \\
\hline $\mathrm{T} \times \mathrm{ES}$ & & & $\begin{array}{c}-0.150^{* * *} \\
(0.052)\end{array}$ & & & & $\begin{array}{c}-0.174^{* * *} \\
(0.047)\end{array}$ & $\begin{array}{c}-0.175^{* * *} \\
(0.059)\end{array}$ \\
\hline $\mathrm{T} \times \mathrm{SS}$ & & & & $\begin{array}{c}0.011 \\
(0.058)\end{array}$ & & & $\begin{array}{c}0.037 \\
(0.049)\end{array}$ & $\begin{array}{c}0.052 \\
(0.054)\end{array}$ \\
\hline $\mathrm{T} \times \mathrm{WS}$ & & & & & $\begin{array}{c}0.040 \\
(0.041)\end{array}$ & & $\begin{array}{l}0.072^{* *} \\
(0.036)\end{array}$ & $\begin{array}{c}0.110^{* * *} \\
(0.039)\end{array}$ \\
\hline $\mathrm{T} \times$ MIIS & & & & & & $\begin{array}{l}0.086^{*} \\
(0.048)\end{array}$ & $\begin{array}{l}-0.014 \\
(0.045)\end{array}$ & $\begin{array}{l}-0.018 \\
(0.045)\end{array}$ \\
\hline Month FE & $x$ & $x$ & $x$ & $x$ & $x$ & $\times$ & $\times$ & $\times$ \\
\hline Year FE & $x$ & $x$ & $x$ & $x$ & $x$ & $x$ & $x$ & $x$ \\
\hline Month $\times$ Year FE & $x$ & $x$ & $x$ & $x$ & $x$ & $x$ & $x$ & $x$ \\
\hline Building FE & $\times$ & $\times$ & $\times$ & $\times$ & $x$ & $\times$ & $\times$ & $\times$ \\
\hline Adj. R-square & 0.555 & 0.555 & 0.557 & 0.555 & 0.555 & 0.556 & 0.558 & 0.460 \\
\hline Observations & 114,594 & 114,594 & 114,594 & 114,594 & 114,594 & 114,594 & 114,594 & 83,355 \\
\hline
\end{tabular}

Notes: This table reports energy savings from the LEED program in federal buildings and the heterogeneity treatment effects regarding different program dimensions with monthly data. The dependent variable is the log of site energy use intensity, and the untreated group is constructed using five-nearest-neighbor $(5 \mathrm{NN})$ matching with replacement. $\mathrm{T}$ is the treatment indicator equal to one if a building $i$ in month $j$ in year $t$ is certified, and zero otherwise. CR stands for certified ratio, and refers to the fraction of a building square footage that is LEED-certified. ES, SS, WS, and MIIS represent the component scores evaluated by the LEED program: energy and atmosphere, sustainable sites, water efficiency, and the combination of material, indoor environment, and innovation, respectively. To facilitate comparison, CR, ES, SS, WS, and MIIS are all standardized to have mean zero and standard deviation one. Column (1) reports the aggregated energy savings from the LEED program. Columns (2)-(6) differentiate the energy savings by each attribute of the LEED program. Columns (7) and (8) show estimates when including all program attributes in the regression. Column (7) reports the results for all buildings, and column (8) restricts attention to office buildings. CDD and HDD are included as controls in all regressions. Because of the potentially repeated non-LEED buildings in the untreated group due to matching with replacement, all regressions are weighted by the inverse of the number of repeated observations. Standard errors clustered by building are reported in parentheses. ${ }^{* * *}$ denotes statistical significance at the $1 \%$ level, ${ }^{* *}$ at the $5 \%$ level, and ${ }^{*}$ at the $10 \%$ level. 
Table A.7: Energy Use Intensity Outcome and Heterogeneity Analysis (Multiple Weights)

\begin{tabular}{lcccccccc}
\hline \hline & $(1)$ & $(2)$ & $(3)$ & $(4)$ & $(5)$ & $(6)$ & $(7)$ & $(8)$ \\
\hline $\mathrm{T}$ & -0.043 & -0.040 & -0.044 & -0.044 & -0.041 & -0.036 & -0.027 & -0.064 \\
& $(0.052)$ & $(0.051)$ & $(0.053)$ & $(0.052)$ & $(0.051)$ & $(0.056)$ & $(0.052)$ & $(0.052)$ \\
$\mathrm{T} \times \mathrm{CR}$ & & & & & & & & \\
& & 0.019 & & & & & 0.043 & 0.032 \\
& & $(0.038)$ & & & & & $(0.043)$ & $(0.034)$ \\
$\mathrm{T} \times \mathrm{ES}$ & & & & & & & & \\
& & & -0.087 & & & & -0.107 & $-0.118^{*}$ \\
& & & $(0.077)$ & & & & $(0.066)$ & $(0.060)$ \\
$\mathrm{T} \times \mathrm{SS}$ & & & & 0.015 & & & 0.022 & 0.037 \\
& & & & $(0.051)$ & & & $(0.045)$ & $(0.045)$ \\
$\mathrm{T} \times \mathrm{WS}$ & & & & & & & & \\
& & & & & 0.023 & & 0.057 & $0.116^{* * *}$ \\
$\mathrm{~T} \times \mathrm{MIIS}$ & & & & & $(0.041)$ & & $(0.035)$ & $(0.033)$ \\
& & & & & & & & \\
& & & & & & $(0.048$ & 0.024 & 0.004 \\
Year FE & $\times$ & $\times$ & $\times$ & $\times$ & $\times$ & $\times$ & $\times$ & $\times$ \\
Building FE & $\times$ & $\times$ & $\times$ & $\times$ & $\times$ & $\times$ & $\times$ & $\times$ \\
Adj. R-square & 0.678 & 0.678 & 0.679 & 0.678 & 0.678 & 0.679 & 0.680 & 0.519 \\
Observations & 9,728 & 9,728 & 9,728 & 9,728 & 9,728 & 9,728 & 9,728 & 7,070 \\
\hline \hline
\end{tabular}

Notes: This table reports energy savings from the LEED program in federal buildings and the heterogeneity treatment effects regarding different program dimensions with multiple weights. The dependent variable is the log of site energy use intensity, and the untreated group is constructed using five-nearest-neighbor $(5 \mathrm{NN})$ matching with replacement. $\mathrm{T}$ is the treatment indicator equal to one if a building $i$ in year $t$ is certified, and zero otherwise. CR stands for certified ratio, and refers to the fraction of a building square footage that is LEED-certified. ES, SS, WS, and MIIS represent the component scores evaluated by the LEED program: energy and atmosphere, sustainable sites, water efficiency, and the combination of material, indoor environment, and innovation, respectively. To facilitate comparison, CR, ES, SS, WS, and MIIS are all standardized to have mean zero and standard deviation one. Column (1) reports the aggregated energy savings from the LEED program. Columns (2)-(6) differentiate the energy savings by each attribute of the LEED program. Columns (7) and (8) show estimates when including all program attributes in the regression. Column (7) reports the results for all buildings, and column (8) restricts attention to office buildings. CDD and HDD are included as controls in all regressions. The regressions are weighted by two variables. First, because of the potentially repeated non-LEED buildings in the untreated group due to matching with replacement, all regressions are weighted by the inverse of the number of repeated observations. Second, we also weight the regressions by building sizes. Standard errors clustered by building are reported in parentheses. ${ }^{* * *}$ denotes statistical significance at the $1 \%$ level, ${ }^{* *}$ at the $5 \%$ level, and ${ }^{*}$ at the $10 \%$ level. 
Table A.8: Energy Use Intensity Impacts from Different Combinations of the Energy and Water Component Scores

\begin{tabular}{|c|c|c|}
\hline & Decrease in ES & 1 S.D. Increase in ES \\
\hline \multicolumn{3}{|c|}{ Panel A: All LEED Buildings } \\
\hline 1 S.D. Decrease in WS & 0.097 & -0.247 \\
\hline 1 S.D. Increase in WS & 0.239 & -0.105 \\
\hline \multicolumn{3}{|c|}{ Panel B: LEED Office Buildings } \\
\hline 1 S.D. Decrease in WS & 0.089 & -0.273 \\
\hline 1 S.D. Increase in WS & 0.307 & -0.055 \\
\hline
\end{tabular}

Notes: This table shows the energy use intensity impacts with different combinations of the energy and water component scores. The values are calculated based on columns (7) and (8) from Table 2 - for all buildings and office buildings, respectively - and they provide an easier way to understand those estimated coefficients. ES and WS in the row and column labels represent component scores of energy and atmosphere and water efficiency, respectively. Each number in this table represents the average percentage change in building energy use when increasing or decreasing one standard deviation (S.D.) of the corresponding score component. For example, at the extremes, a building that had a one standard deviation higher energy score than average and one standard deviation lower water score than average would have energy use that was $24.7 \%$ lower than a non-LEED building. 